\title{
Ultrasound-responsive polymer-based drug delivery systems
}

\author{
Ping Wei ${ }^{1}$ Erik Jan Cornel ${ }^{1} \cdot$ Jianzhong $\mathrm{Du}^{1,2}(\mathbb{0}$
}

Accepted: 11 March 2021 / Published online: 24 March 2021

(c) Controlled Release Society 2021

\begin{abstract}
Ultrasound-responsive polymeric materials have received a tremendous amount of attention from scientists for several decades. Compared to other stimuli-responsive materials (such as UV-, thermal-, and pH-responsive materials), these smart materials are more applicable since they allow more efficient drug delivery and targeted treatment by fairly non-invasive means. This review describes the recent advances of such ultrasound-responsive polymer-based drug delivery systems and illustrates various applications. More specifically, the mechanism of ultrasound-induced drug delivery, typical formulations, and biomedical applications (tumor therapy, disruption of blood-brain barrier, fighting infectious diseases, transdermal drug delivery, and enhanced thrombolysis) are summarized. Finally, a perspective on the future research directions for the development of ultrasound-responsive polymeric materials to facilitate a clinical translation is given.
\end{abstract}

Keywords Ultrasound-responsive $\cdot$ Polymeric materials $\cdot$ Drug delivery $\cdot$ Targeted therapy $\cdot$ Infectious diseases

\section{Introduction}

"Smart" or stimuli-responsive materials can change their physicochemical properties in response to external stimuli. Various types of chemical, physical, or biochemical stimuli (such as $\mathrm{pH}$, temperature, enzymes, ultrasound) have been used to affect the physicochemical properties of such smart materials $[1,2]$.

Ultrasound waves are mechanical waves with high frequencies ( $\geq 20 \mathrm{kHz}$ ) that can be focused and spread through certain media [3]. Such waves have been used in many clinical applications as a non-invasive and cost-effective modality, including in vivo imaging [4], physiotherapy [5, 6], cosmetics [7], and food industry [8]. Moreover, highintensity focused ultrasound (HIFU) can be used to generate local hyperthermia for cell ablation in targeted tissues [9-11]. In addition to the above implementations, increasingly important applications of ultrasound waves can

Jianzhong Du

jzdu@tongji.edu.cn

1 Department of Polymeric Materials, School of Materials Science and Engineering, Key Laboratory of Advanced Civil Engineering Materials of Ministry of Education, Tongji University, 4800 Caoan Road, Shanghai 201804, China

2 Department of Orthopedics, Shanghai Tenth People's Hospital, Tongji University School of Medicine, Shanghai 200072, China be found in drug delivery $[12,13]$. This is because one of the most significant challenges in the development of drug delivery systems is how to facilitate site specificity $[14,15]$. This challenge can be overcome with ultrasound-responsive carriers since this approach allows a non-toxic pathway that enables spatiotemporally targeted drug release $[16,17]$. Therefore, the synergetic use of polymer-based materials and ultrasound has been widely used in a large number of biomedical applications.

Ultrasound-responsive polymeric materials have gained special attention since ultrasound is invasive and polymer materials are chemically versatile and can be biodegradable. Commonly used ultrasound-responsive polymer-based materials include polymer-coated bubbles/emulsions (microbubbles [18], nanobubbles [19, 20], nanodroplets [21, 22], and nanoemulsions [23]), polymer vesicles/micelles [24, 25], and polymer hydrogels [26]. Various drugs (such as small drug molecules, proteins [27], and DNA [28]) can be delivered with the use of these ultrasound-responsive drug delivery vehicles. These vehicles can be used for a variety of applications, including tumor therapy [29], disruption of the blood-brain barrier [30], fighting infectious diseases, transdermal drug delivery [31], and thrombolysis [32]. Herein, an overview on ultrasound-responsive polymer-based drug delivery systems is given. Thereafter, mechanisms, various representable formulations, and the current status of preclinical and clinical applications are discussed. Finally, this 
review is concluded with a perspective on the required future work to facilitate a clinical translation of these drug delivery systems.

\section{Mechanism of ultrasound-induced drug delivery}

Despite the vast amount of research on ultrasound-assisted drug delivery and therapeutic applications thereof, the mechanism of ultrasound-induced drug delivery remains elusive. Nevertheless, the mechanism is likely related to thermal and non-thermal effects produced by ultrasound radiation energy. This section highlights these two effects.

The thermal effect can be defined as the transfer of acoustic energy to thermal energy, causing a temperature increase within the irradiated tissue. This leads to perturbation of the cell membrane and an increased permeability of the blood vasculature [33-35]. Such a hyperthermia approach has shown significant improvements in tumor therapy, with targeted triggered release from thermosensitive liposomes [36-39], microbubbles [40], or polymeric micelles [41].

The second potential mechanism for ultrasound-mediated drug delivery, the non-thermal effect, is primarily associated with cavitation [42]. Cavitation can occur in native microbubbles or cavitation nuclei such as microbubbles or nanobubbles [43]. It can be classified into two distinct forms [44, 45]: non-inertial and inertial cavitation. The former, non-inertial (or stable) cavitation, comprises a sustainable cycle of bubble expansion and contraction. This non-inertial cavitation can be enhanced by ultrasound-responsive agents (such as microbubbles, nanobubbles, nanodroplets, etc.) for therapeutic applications [46-48]. The second form of cavitation, inertial (or transient) cavitation, refers to the violent collapse of bubbles along with high-speed microstream and the generation of free radicals $[49,50]$. Ultrasound-triggered drug release from loaded block copolymer micelles or vesicles was most probably achieved via shear stress and shockwaves from the collapse of bubbles [42].

The cavitation activity can result in some biological effects including sonoporation and enhancement of vascular permeability [51, 52]. The former, sonoporation, is a phenomenon of improved intracellular drug uptake due to the increased porosity and permeability of the irradiated cell membranes [53, 54]. This permeabilizing effect has also been termed as sonophoresis or phonophoresis in transdermal drug delivery [55, 56]. The latter, enhancement of vascular permeability, is the subject of clinical and preclinical studies, which aim at opening the blood-brain barrier (BBB) in a non-destructive way [57-59]. The targeted ultrasoundinduced disruption of BBB has shown to be an effective approach to deliver drugs to the brain [60].

\section{Commonly used polymeric carriers for ultrasound-mediated drug delivery}

\section{Microbubbles}

Microbubbles are gas-filled objects that are widely used as ultrasound-responsive drug carriers and contrast agents for many decades [61]. These microbubbles are micron-sized $(1-10 \mu \mathrm{m})$ and stabilize a gas phase within a shell. The firstgeneration microbubbles are unstable air-filled bubbles that suffer from a short storage life and therefore disappear rapidly from the bloodstream $[62,63]$. This problem was improved upon with the development of the second-generation microbubbles. These bubbles are filled with long-lived hydrophobic gases, such as sulfur hexafluoride or perfluorocarbons. The microbubble membrane is usually composed of surfactants, proteins, saccharides, or lipids [64]. These microbubbles have a good ultrasonic response signal and offer a good amount of contrast; however, it is difficult to predict and control the size distribution of this species during preparation. Additionally, the ultrasonic properties of the second-generation microbubbles cannot be controlled, owing to the inherent limitations of the membrane-forming materials (i.e., chemical modifications are difficult to achieve). Encouragingly, various synthetic and natural polymer-shelled microbubbles have emerged with superior advantages compared to the above second generation microbubbles. These polymer-shelled microbubbles offer the advantage of being more stable and the ability to carry larger amounts of payload than their lipid-coated counterparts [65]. These microbubbles also allow adjustment of the chemical composition and the polymer molecular weight, which leads to accurate control of the elasticity of the shell [66, 67]. Moreover, the polymer shell may provide microbubbles with an increased circulation time and a higher ligand density for efficient tissue targeting [68]. Therefore, these kinds of microbubbles have gained much attention and are promising materials for use in ultrasound contrast agents or as drug carriers (Table 1).PLA poly(lactic acid), PAH poly(allylamine hydrochloride), PFC perfluorocarbon, PVA polyvinyl alcohol, PLGA poly(lactic-co-glycolic acid), PFO-PLLA perfluoroctanol-poly(lactic acid

To date, there are several methods available for preparing drug-loaded polymeric microbubbles: (1) co-encapsulation of drugs within the microbubble core [69, 70], (2) physical association of drugs with the polymeric shell [71], and (3) covalent linkage of drugs with the polymeric shell [72].

\section{Nanobubbles and nanodroplets}

Although microbubbles have been widely used (as discussed in the previous section), there are several disadvantages that need to be considered when they are used as drug delivery 
Table 1 Various polymershelled microbubbles as drug carriers

\begin{tabular}{lllll}
\hline Shell composition & Gas core & Size range $(\mu \mathrm{m})$ & Fabrication Method & Ref. \\
\hline PLA & Air & $1-2$ & Double emulsion technique & {$[73]$} \\
PAH and albumin & PFC & $5-20$ & Layer-by-layer coating & {$[74]$} \\
PLA & $\mathrm{N}_{2} /$ oil & $2-3$ & Premix membrane emulsification & {$[75]$} \\
PVA & Air & $3-4$ & Cross-linking reaction at the air/water & [76] \\
& & & interface & \\
PLGA & PFC & $0.8-0.9$ & Double emulsion technique & {$[69]$} \\
PFO-PLLA & Air & $2-5$ & Emulsion-evaporation technique & {$[77]$} \\
\hline
\end{tabular}

$P L A$ poly(lactic acid), $P A H$ poly(allylamine hydrochloride), $P F C$ perfluorocarbon, $P V A$ polyvinyl alcohol, $P L G A$ poly(lactic-co-glycolic acid), $P F O-P L L A$ perfluoroctanol-poly(lactic acid) vehicles. These disadvantages are associated with their relatively large size and short circulation times [78]. More specifically, the delivery of drugs in vasculature sites can be hindered because microbubbles are constrained to the intravascular space and are too large to exit the vasculature. For this reason, only endothelium region can be targeted [79-81]. Indeed, much smaller nanoscale-sized particles are required. Nanobubbles and nanodroplets with sizes smaller than $1 \mu \mathrm{m}$ have been explored as alternative agents for ultrasound-responsive drug delivery and showed an improved intracellular uptake compared to micro-sized bubbles [33, 82]. Here, it is perhaps worthy to emphasize that nanobubbles consist of a polymer-coated gas core, while nanodroplets consist of a polymer-coated liquid core [83].

Nanobubbles are mainly prepared by sonication in the presence of a fluorinated gas, such as perfluorocarbons or sulfur hexafluoride [84]. The submicron size of the nanobubbles makes them suitable for drug delivery, ultrasound imaging, and other treatments such as cancer therapy [20, 85]. Whereas nanodroplets are usually composed of perfluorocarbon (PFC) and coated materials. They are stable in the blood stream, showing much greater potential as drug carriers [86-88]. When exposed to ultrasound at targeted site, the PFC nanodroplets undergo an instant phase transition into gas bubbles. This process is known as acoustic droplet vaporization [89]. Additionally, they are relatively stable in the blood stream, enabling their use as an ultrasound-responsive drug carrier. Nanobubbles or nanodroplets can be suitable for drug delivery; however, the preparation of stable nanobubbles or nanodroplets is currently challenging [90-93]. Fortunately, advances in nanoemulsion preparation methods were made to overcome such limitations, as discussed in the next section.

\section{Nanoemulsions}

Nanoemulsions are mixtures of two immiscible liquids that is stabilized by amphiphilic copolymers or surfactants [94]. Recently, a large amount of interest has been devoted to the use of nanoemulsions as phase-changing contrast agents and in drug delivery, owing to their longer recirculation time, stability, and convenient preparation. For instance, Pozzo and coworkers exploited a polypyrrole coated PFC nanoemulsions via the ouzo approach [95]. Here, core-shell PFC nanoemulsions with a relatively small size of $184 \mathrm{~nm}$ were obtained. These nanoemulsions provided a much lower sonophotoacoustic activation threshold, a characteristic that is useful for the development of clinically safe applications.

Airan and coworkers reported another PFC nanoemulsion that can be used as an ultrasound-activated wireless drug infusion catheter [96]. Different kinds of hydrophobic drugs can be encapsulated into these nanoemulsions, and the drug loading efficiency was increased with the hydrophobicity of encapsulated drugs. More importantly, all components of this nanoemulsion are currently widely used in clinical trials; therefore, these polymeric PFC nanoemulsions might be a promising clinically translatable platform for ultrasoundresponsive drug delivery.

\section{Polymeric vesicles/micelles}

Polymer vesicles and micelles are generally self-assembled from amphiphilic block copolymers [97-99]. Polymer vesicles are hollow nanometer-sized spheres with a bilayer or interdigitated membrane and hydrophilic coronas [100-102], whereas polymer micelles consist of a solid core instead of a lumen. The stable and robust properties of these nanoparticles make them suitable for controlled drug delivery $[103,104]$.

A good example of an ultrasound-responsive polymer vesicle was reported by Du and coworkers: Polymer vesicles were self-assembled from a poly(ethylene oxide)block-poly[2-(diethylamino)ethyl methacrylate-stat-2-tetrahydrofuranyloxy)ethyl methacrylate] [PEO- $b$-P(DEA-statTMA)] block copolymers. These vesicles were responsive to both physical (ultrasound) and chemical (pH) stimuli [105]. Ultrasound irradiation of the polymer vesicles induced a significant reduction in vesicle size, as a result of the fast disruption and re-self-assembly of vesicle membrane. ${ }^{1} \mathrm{H}$ NMR analysis indicated that a physical rather than chemical process occurred during this rearrangement process. Moreover, these dually responsive vesicles can encapsulate anti- 
cancer drugs during self-assembly and showed controlled drug release behavior when subjected to ultrasound radiation or when the solution $\mathrm{pH}$ was reduced. This study shows the development of an ultrasound-responsive polymer vesicle for controlled drug release; however, unfortunately, the underlying mechanism of the controlled ultrasound responsiveness remains unclear. In the subsequent studies from the same group, Yang et al. unveiled a new insight into the origin and the key regulating factors of the ultrasound responsiveness of the polymer nanoparticles [106, 107]. They demonstrated that the intrinsic ultrasound responsiveness thermodynamically originates from metastable states: Sonication can accelerate the response rate by promoting hydrophobic chain movement to a more stable state. In particular, metastable polymer vesicles with good ultrasound responsiveness can be achieved when the self-assembly temperature $\left(T_{\mathrm{s}}\right)$ is around (or slightly below) the glass transition temperature $\left(T_{\mathrm{g}}\right)$ of the hydrophobic segment of the used block copolymers. Additionally, the response rate of such metastable vesicles can be enhanced by raising the sonication temperature $\left(T_{\mathrm{u}}\right)$. Interestingly, solid polymer micelles, and vesicles at stable state, are not ultrasound sensitive (Fig. 1). This finding is important since it lays a foundation for the judicious design of the next-generation ultrasound-responsive drug delivery vehicles.

In another group, Zhou and coworkers designed an ultrasound-responsive ultrathin multiblock copolyamide vesicle [108]. Different from the fast disruption and rearrangement of the polymer vesicles discussed in the previous section, these copolyamide vesicle membranes are disturbed by sonication, leading to the release of encapsulated hydrophobic drugs. The authors attributed this ultrasonic responsive behavior to the disruption of intermolecular hydrogen bonds within the vesicles.
In addition to polymer vesicles, ultrasound-responsive polymer micelles have also received a considerable amount of attention. Zhao and coworkers prepared a poly(ethylene oxide)-block-poly(2-tetrahydropyranyl methacrylate) (PEO- $b$-PTHPMA) block copolymer that could spontaneously form micelles with a PTHPMA core and PEO corona in water [109]. HIFU irradiation induced the conversion of the hydrophobic THPMA units into hydrophilic methacrylic acid groups (Fig. 2a). This led to the disruption of the polymer micelles and to the release of their molecular cargo (Nile red). Building upon this finding, Xuan et al. reported ultrasound-responsive micelles by introducing a HIFU-labile THPMA units into the core-forming block [110]. Hydrolysis of the PTHPMA made this block copolymer more hydrophilic, which in turn increased the LCST of the thermo-responsive polymer from 25 to $42{ }^{\circ} \mathrm{C}$. Consequently, these polymer micelles disassembled when exposed by HIFU irradiation (Fig. 2b).

Xia and coworkers further developed central disulfide and mechano-labile ester bond-based ultrasound-responsive mechanophores [111, 112]. Disulfide bonds were included in the polymer as reduction-responsive groups, and the ester bonds could be hydrolyzed with HIFU irradiation. Therefore, these copolymer micelles were responsive to both redox agent and physical stimulus (HIFU irradiation). However, it should be noted that the release of the pyrene payloads was more efficient under HIFU irradiation, compared to the redox-induced release. These studies established the ultrasound-responsive copolymer micelles based on mechanolabile ester bonds; however, the effect of ultrasound on disulfide bonds, and whether this cleavage is suitable for in vivo applications, has not yet been studied in depth.
Fig. 1 Illustration of ultrasound responsiveness of block copolymer nanoparticles (different colors represent different nanoparticles). The initially presented thermodynamic state of the nanoparticle dictates the ultrasound responsiveness. Regulating factors are the $T_{\mathrm{s}}$ and solvent. The ultrasound responsive rate is dictated by the $T_{\mathrm{u}}$; a higher temperature leads to a faster response rate. Reproduced with permission from [106]

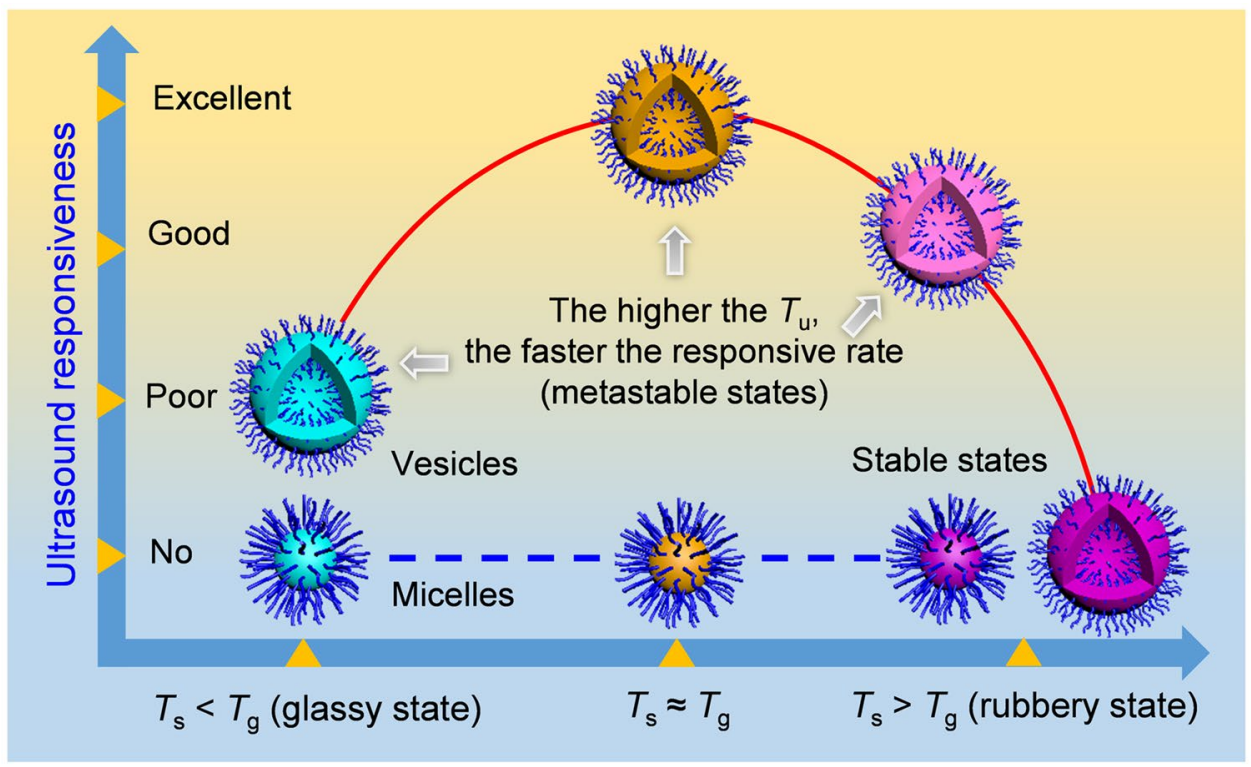


Fig. 2 a Ultrasound-induced hydrolysis of ester groups to form $\mathrm{PEO}_{\mathrm{x}}-\mathrm{PMA}_{\mathrm{y}}$. Reproduced with permission from [109]. b Schematic illustration of the amplification mechanism for ultrasound-disrupted block copolymer micelles based on an ultrasound-induced increase in the lower critical solution temperature (LCST) of the hydrophobic block. Reproduced with permission from [110]
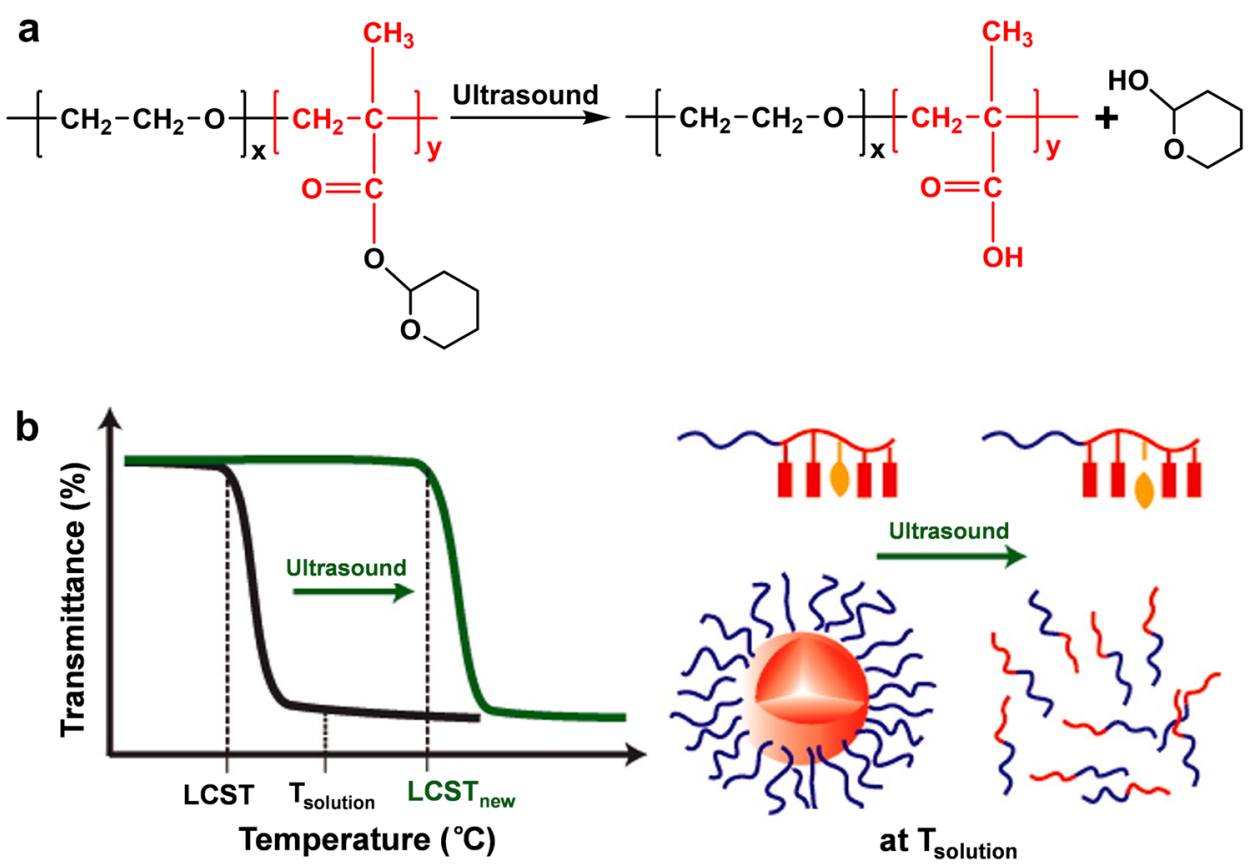

\section{Polymeric hydrogels}

Polymeric hydrogels are micron-sized cross-linked networks capable of absorbing large amounts of water [113]. The previously described ultrasound-responsive polymeric carriers are generally used to load small molecule drugs, whereas three-dimensional polymeric hydrogels are promising as delivery systems of biomacromolecular drugs (such as proteins [114], antibodies [43], or oligonucleotides [115, 116]).

For example, Mooney and coworkers reported a self-healing cross-linked hydrogel capable of ultrasound-triggered drug release [26]. These hydrogels were prepared from alginate cross-linked with $\mathrm{Ca}^{2+}$. It was shown that ultrasound does not permanently damage the hydrogel structure but enables the release of drugs. Furthermore, another chitosan tripolyphosphate cross-linked ionic hydrogel was evaluated and showed similar characteristics in the same study. In another group, Yamaguchi et al. developed a synthetic hydrogel as an ultrasound-responsive protein carrier [27]. This supramolecular polymeric hydrogel is cross-linked with a host-guest interaction of $\beta$-cyclodextrin and adamantine. This material is more susceptible to low-energy ultrasound than chemically cross-linked hydrogels. Here, ultrasound causes mechanical stress-induced cleavage of these host-guest bonds and triggers the degradation of the hydrogel. These findings may provide important new insights for the development of ultrasound-responsive hydrogels.

A comparative summary of various ultrasound-responsive polymeric drug carriers is presented in Table 2. Each carrier has its unique advantages (e.g., polymeric microbubbles are widely used as ultrasound imaging agents and can significantly improve ultrasound signals. Polymeric vesicles have improved stability and allow chemical functionalization). However, some of these carriers suffer from certain limitations in terms of their size, stability, or drug loading capacity [121]. More in-depth studies are required to realize a future clinical transition.

\section{Various biomedical application of ultrasound-responsive polymeric carriers}

\section{Tumor therapy}

Ultrasound waves have a deep tissue penetration ability; this makes them suitable for the treatment of tumor tissue in combination with ultrasound-responsive formulations [122-126]. Furthermore, ultrasound can accurately control the drug release rate of such materials [127, 128]. Recently, Du and coworkers [24] designed a novel ultrasound-responsive vesicle that is based on the copolymer poly(ethylene oxide)-block-poly(2(diethylamino)ethyl methacrylate)-stat-poly(methoxyethyl methacrylate) [PEO- $b$-P(DEA-stat-MEMA)] (Fig. 3). These polymeric vesicles exhibit relatively high drug loading efficiency $(21.3 \%)$ and good $\mathrm{pH} / \mathrm{ultrasound}$-controlled drug release behavior. In vivo studies showed that the combined treatment of drug-loaded vesicles (DOXvesicles) with sonication could effectively suppress tumor growth (95\% reduction in tumor mass). Here, sonication improved the accuracy of the treatment and minimized systematic adverse side effects in mice models (Fig. 4a). 
Table 2 Comparison of ultrasound-responsive polymeric drug carriers

\begin{tabular}{|c|c|c|c|c|c|c|c|}
\hline \multirow[t]{2}{*}{ Carriers } & \multirow[t]{2}{*}{ Size range } & \multirow{2}{*}{$\begin{array}{l}\text { Particle distribu- } \\
\text { tion }\end{array}$} & \multicolumn{2}{|c|}{ Drug loading efficiency } & \multirow{2}{*}{$\begin{array}{l}\text { Ultrasound imag- } \\
\text { ing }\end{array}$} & \multirow[t]{2}{*}{ Disadvantages } & \multirow[t]{2}{*}{ Ref. } \\
\hline & & & Hydrophilic & Hydrophobic & & & \\
\hline $\begin{array}{r}\text { Microbubbles/ } \\
\text { nanobubbles }\end{array}$ & $1-10 \mu \mathrm{m} / 0.1-1 \mu \mathrm{m}$ & Polydisperse & Low & Moderate & Possible & $\begin{array}{l}\text { Polydispersity, } \\
\text { lack of long- } \\
\text { term stability }\end{array}$ & {$[20,85,117]$} \\
\hline Nanodroplets & $200-1000 \mathrm{~nm}$ & Monodisperse & Moderate & High & $\begin{array}{l}\text { Possible upon } \\
\text { activation }\end{array}$ & $\begin{array}{l}\text { Different activa- } \\
\text { tion efficiency }\end{array}$ & {$[88,118]$} \\
\hline Nanoemulsions & $100-500 \mathrm{~nm}$ & Monodisperse & Moderate & High & $\begin{array}{l}\text { Possible upon } \\
\text { activation }\end{array}$ & $\begin{array}{l}\text { Phase shift is } \\
\text { required }\end{array}$ & {$[33,95]$} \\
\hline Vesicles & $100-600 \mathrm{~nm}$ & Monodisperse & High & High & Not applicable & $\begin{array}{l}\text { Some are not } \\
\text { biodegradable }\end{array}$ & {$[108,119]$} \\
\hline Micelles & $10-100 \mathrm{~nm}$ & Monodisperse & Low & High & Not applicable & $\begin{array}{l}\text { Responsive to } \\
\text { high intensity } \\
\text { ultrasound }\end{array}$ & {$[109,110,120]$} \\
\hline Hydrogels & Not applicable & Not applicable & High & High & Not applicable & $\begin{array}{l}\text { Only act as a } \\
\text { depot }\end{array}$ & {$[27,116]$} \\
\hline
\end{tabular}

More specifically, a near-infrared fluorescent probe (indocyanine green (ICG)) was used to label the vesicles.

In vivo fluorescence imaging results demonstrated that local ultrasound irradiation promoted the anticancer drug release from the vesicles and allowed the ICG to penetrate the tumor tissue (Fig. 4a, bottom right). Similar ultrasoundenhanced targeting accumulation has also been demonstrated by other groups [130].
In other studies, Shuai and coworkers developed various gas-filled polymeric carriers for cancer treatment [29, 131, 132]. For example, a theranostic nanodroplet with encapsulated perfluoro- $n$-pentane (PFP), pentafluorobutane (PFB), and DOX (PFP/PFB/DOX-PPEHD) were used for imaging and as anticancer drug vehicle [129]. Such $\mathrm{pH}$ responsive nanodroplets have a size of $178 \mathrm{~nm}$ during circulation and expanded to $437 \mathrm{~nm}$ when exposed to the acidic tumor microenvironment. This size increase would lower

Fig. 3 Illustration of ultrasoundresponsive DOX vesicles for controlled drug delivery in tumor cells. Both external tumor site sonication and $\mathrm{pH}$ reduction in the late endosome can promote rapid drug release. Reproduced with permission from [24]

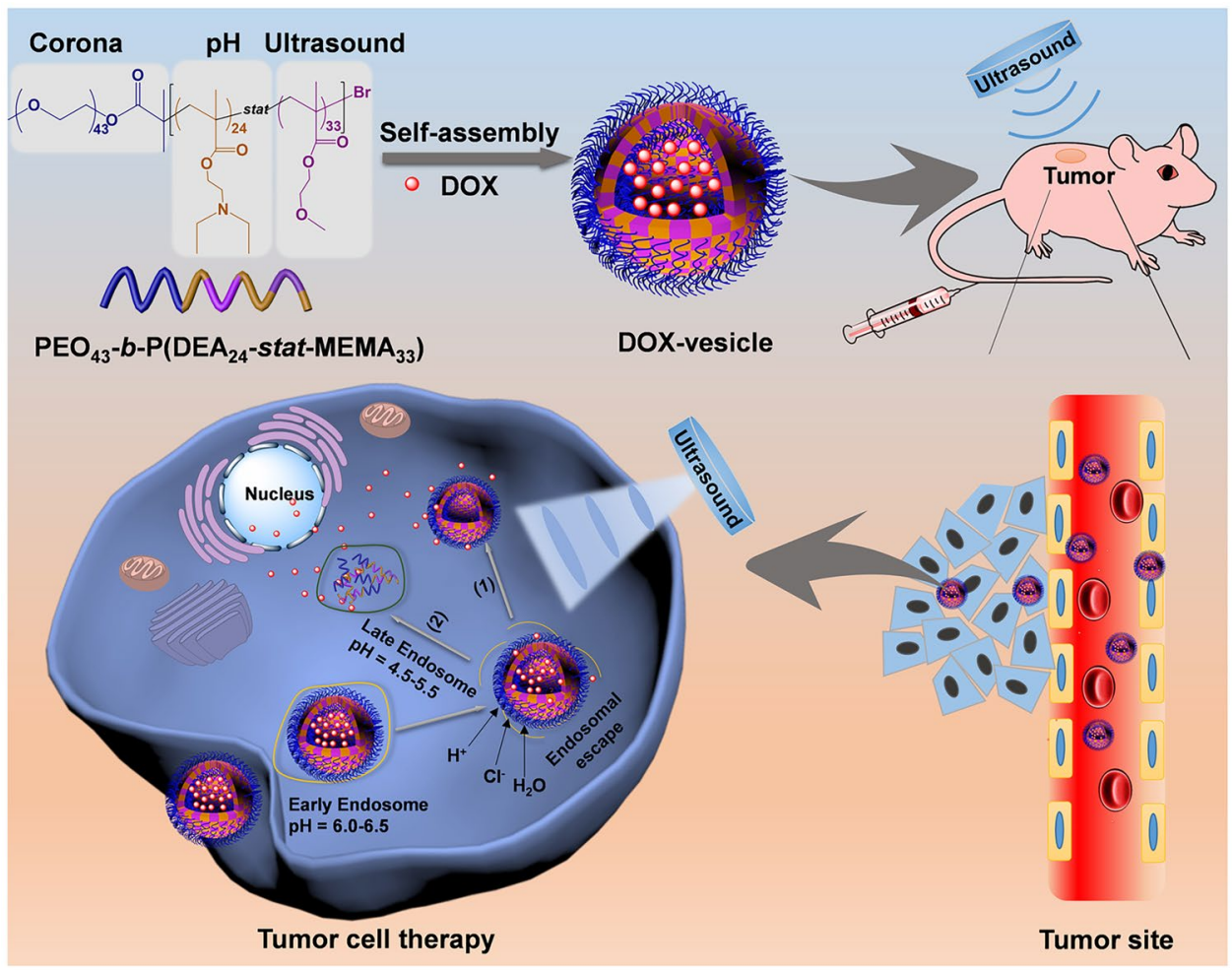


Fig. 4 a Antitumor effects in vivo. Top: tumor growth curves, body weight changes during treatment; bottom: representative photographs of tumors after treatment, and in vivo fluorescence imaging of nude mice bearing HeLa tumors after treated with free ICG, ICG vesicles, and ICG vesicles with sonication. Reproduced with permission from [24]. b Deep tissue penetration. Left: schematic illustration for the LFUS-promoted DOX release in deep tissue penetration; right: confocal laser scanning microscopy (CLSM) observation of frozen tumor sections of mice C6 glima obtained $2 \mathrm{~h}$ after LFUS irradiation in mice receiving DOX-containing nanodroplets. The red and green fluorescence were attributed to DOX and fluorescein isothiocyanate (FITC) labeling of tumor blood vessels. Reproduced with permission from [129]
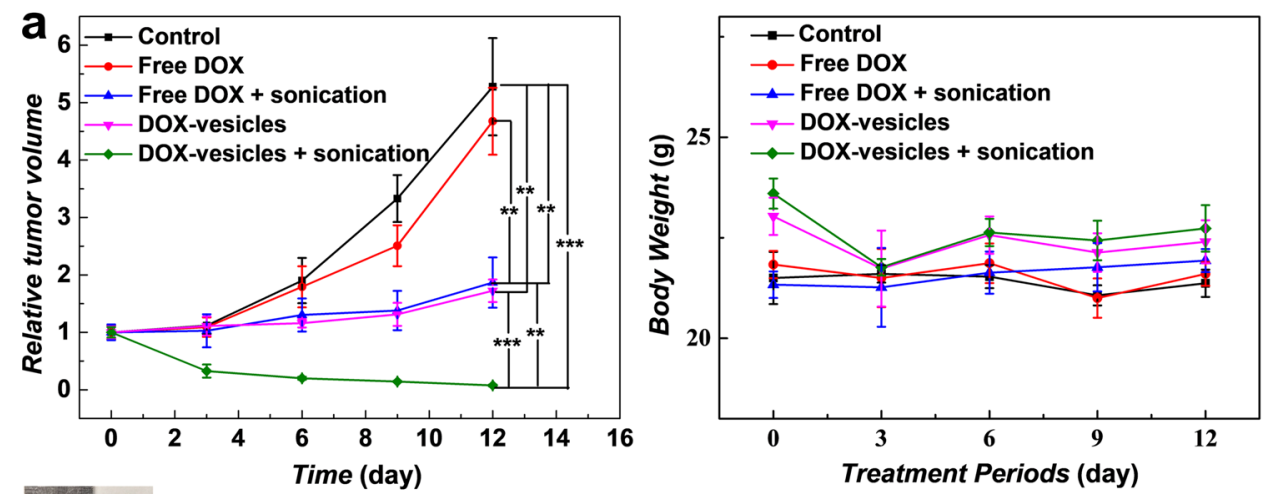

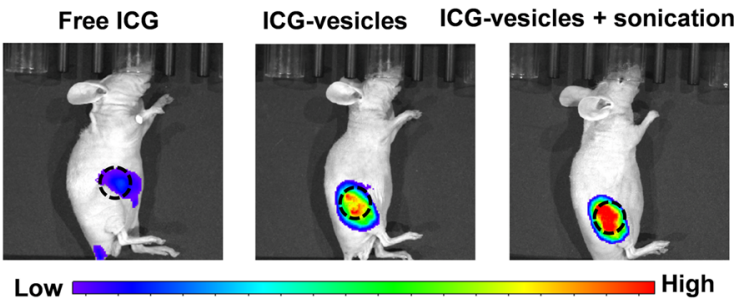

b

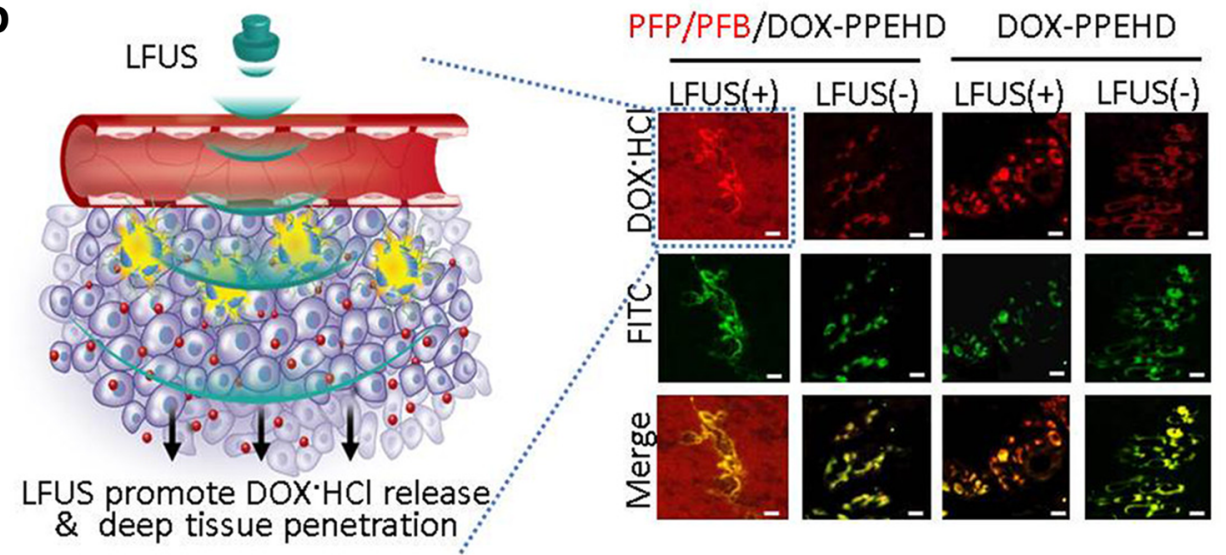

the vaporization threshold of the encapsulated PFC. Local heating of these expanded nano-objects led to the conversion from nanodroplets-to-echogenic bubbles at the tumor site. Subsequent low frequency ultrasound irradiation (LFUS, $1 \mathrm{MHz}$ ) induced deep tissue chemotherapy by releasing the molecular cargo. Mice treated with PFP/PFB/DOX-PPEHD/ LFUS( + ) showed strong DOX fluorescence throughout the tumor area (Fig. 4b). The pH-induced morphological transition was also applied in other works where ultrasoundsensitive vesicles were used for deep tissue-penetrating drug delivery and effective cancer therapy [133].

\section{Disruption of blood-brain barrier}

The BBB is a specialized blood vessel wall structure that is formed from densely packed brain endothelial cells [134, 135]. It is a significant barrier in the body that only allows the uptake of small lipophilic drugs and, therefore, prevents most therapeutic drugs (and toxic compounds) from entering the central nervous system [60, 136, 137]. Noninvasive focused ultrasound has been exploited to open the BBB in a targeted manner. It has been well documented that ultrasound treatment in combination with microbubbles holds a significant promise for shuttling large therapeutic molecules (such as antibodies, growth factors, and nanomedicines) across the BBB [138-141]. For example, Davies and coworkers reported a polymer-stabilized microbubble for brain-targeted drug delivery [142]. The model fluorescent dye NR668 was used in this study to explore the release and delivery behavior of this microbubble. In vivo studies demonstrated, with the assistance of focused ultrasound, that these self-assembled microbubbles were able to cross the BBB via transcytosis.

In addition to microbubbles, nanodroplets with a relatively smaller size, ranging between 200 and $500 \mathrm{~nm}$, have also been used with focused ultrasound-induced BBB opening [143]. Phase shift nanodroplets with PEGylated PLGA-based shell and liquid perfluoropentane cores were 
designed to disrupt the BBB in rat models [144]. Significant extravasation of Evan's blue and satisfied biosecurity can be achieved at the acoustic pressure of 1.0 MPa. Moreover, these nanodroplets showed enhanced focused performance and high precision on BBB opening compared to lipid microbubbles.

\section{Fighting infectious diseases}

Ultrasound has great potential for the treatment of infectious diseases, especially when limited resources are available [145]. Abdominal [146], gastrointestinal [147], lung [148], and intrauterine ultrasound imaging [149] are widely used for the screening of clinical infectious diseases. Additionally, with the development of nanotechnology-based drug delivery systems, ultrasound-induced drug delivery has shown much potential against bacteria, biofilms, pathogenic viruses, and other microbial diseases [150, 151]. For instance, Ma et al. prepared PLGA-based antifungal nanoparticles which were loaded with amphotericin $\mathrm{B}$ via the double emulsion method. LFUS irradiation $(42 \mathrm{kHz})$ combined with these loaded nanoparticles significantly enhanced the antifungal efficiency on $C$. albicans. In another group, Stoodley and coworkers, developed a drug delivery polymer matrix that was prepared from a poly(2-hydroxyethyl methacrylate) (PHEMA) hydrogel. This gel was coated with ordered methylene chains that formed an ultrasoundresponsive outer layer [152]. This hydrogel could retain the drug ciprofloxacin and a significant drug release occurred upon low-intensity ultrasound irradiation. It was shown that this material could be used to significantly reduce Pseudomonas aeruginosa biofilm accumulation.

Other kinds of infectious diseases that are hard to treat are parasitic infections in the central nervous system. Polymeric nanoparticles have shown to be effective for the treatment of such diseases [153,154]. As discussed in "Disruption of blood-brain barrier" section, ultrasound-responsive polymeric carriers are able to deliver drugs across the BBB [30]. This treatment method could also be used as a potential new treatment strategy for brain infectious diseases, leading to enhanced drug accumulation and bioavailability in the central nervous system.

\section{Transdermal drug delivery}

The applicability of ultrasound to deliver therapeutic cargos through the skin is referred to as sonophoresis [155, 156]. There are two types of sonophoresis that can de distinguished based on the applied frequencies: Lowfrequency sonophoresis utilizes frequencies within the range of $20-100 \mathrm{kHz}$, and high-frequency sonophoresis utilizes frequencies within the range of $0.7-16 \mathrm{MHz}$ [157]. Sonophoresis is more efficient when performed at low ultrasound frequencies. In the early 1990s, Tachibana et al. reported the application of low-frequency ( $48 \mathrm{kHz}$ ) ultrasound-enhanced transdermal transport of lidocaine and insulin across hairless rat skin in vivo $[158,159]$. The blood glucose levels decreased more rapidly for the groups treated with low-frequency $(34 \pm 11.9 \%)$ compared to the high-frequency groups $(22.4 \pm 3.9 \%)$, after $120 \mathrm{~min}$ of ultrasound exposure. Langer and coworkers found that low-frequency sonophoresis is more effective because it enhances skin permeability [160]. Medicines, including low molecular weight therapeutic drug (corticosterone) and high molecular weight proteins (insulin, interferon $\gamma$ and erythropoietin), could be successfully delivered across the skin with low-frequency ultrasound of $20 \mathrm{kHz}$.

In addition to sonophoresis, ultrasound-responsive carriers with controlled drug release have their own advantages in transdermal delivery. Huang et al. fabricated an ultrasoundresponsive transdermal drug delivery system by embedding diclofenac sodium-loaded polyester microcapsules into a hydrogel patch [161]. Here, ultrasound can be used to trigger the release of drug and aid efficient skin penetration. Further ex vivo and in vivo transdermal drug release studies demonstrated that improved and controlled transdermal delivery of diclofenac sodium was achieved. In another group, Vittorio and coworkers designed an ultrasound-responsive PLGA microplate that was loaded with curcumin and allowed the on-demand drug release [162]. Both high-frequency and low-frequency ultrasound could be used to release the encapsulated drugs; however, longer radiation times were required for the latter to achieve the same amount of released drug. This approach might be applied in the fabrication of transdermal drug delivery system, but more in vivo studies need to be performed to further develop this emerging technology.

Additionally, recent improvements in physical permeation enhancement technologies (i.e., electroporation, iontophoresis, and microneedle array patches) have led to an increased amount of interest in transdermal drug delivery [163-168]. It can be expected that the combination of ultrasound-responsive polymeric formulations with these advanced technologies might further enhance transdermal drug delivery [156, 169]. The synergistic combination of microneedles with ultrasound-responsive drug carriers has been reported in 2020: Lim and coworkers utilized an ultrasonically and iontophoretically enhanced transdermal delivery platform that allowed rapid and localized drug delivery [170]. This platform consisted of hyaluronic acid microneedles that showed an increased dissolution rate under ultrasonic stimulation $(1.7 \mathrm{MHz})$, or under continuous exposure of an electric field. Their data show that this exposure allowed the positively charged Rhodamine B to efficiently penetrate a tissue mimicking gelatin gel. Therefore, such a synergistic combination strategy is expected to yield a promising platform technology for transdermal drug delivery systems. 


\section{Enhanced thrombolysis}

Advances in ultrasound-guided drug delivery for the treatment of thrombotic diseases have shown potential [171-175]. A novel urokinase-loaded nanogel was designed for ultrasound-triggered thrombolysis [176]. In this study, the clinical available urokinase-type plasminogen activator (uPA) $[177,178]$ was encapsulated into the hollow nanogels formed by poly (ethylene glycol) crosslinked glycol chitosan (Fig. 5a). The authors demonstrated that these uPA-loaded nanogels have a prolonged lifetime compared to free uPA. Fast uPA release from the nanogel could safely be achieved with an ultrasound diagnostic frequency of $2 \mathrm{MHz}$. Additionally, the thrombolysis rate of blood clots can be efficiently accelerated.

In another study, poly(isobutyl cyanoacrylate) (PIBCA) microbubbles with different polysaccharide coatings were fabricated via a one-pot polymerization protocol (Fig. 5b) [179]. Among these various microbubbles, fucoidan-functionalized microbubbles (fucoidan-MBs) exhibited high affinity to P-selectin, an adhesion molecule that is especially expressed at thrombus sites. This feature enabled the fucoidan-MBs to reach the thrombus efficiently and to achieve real-time diagnosis of the thrombus site. The localized fucoidan-MBs degraded by exposure to a destructive pulse, indicating that these fucoidan-MBs are a promising theranostic platform for thrombolysis treatment when incorporated with antithrombotic or fibrinolytic drugs. Further exploration of such thrombolytic therapy is required to proof the efficiency of this promising concept.

\section{Conclusion and perspective}

Recent advances in ultrasound-responsive polymer-based drug delivery systems are summarized in this review. The mechanism of ultrasound-assisted drug delivery is highlighted, and biomedical applications in cancer therapy, disruption of $\mathrm{BBB}$, fighting infectious diseases, transdermal drug delivery, and thrombolysis are discussed. Commendable achievements have been made, but there are important problems that need to be resolved to make ultrasoundresponsive polymeric carriers suitable for potential clinical application:

(1) Ultrasound-responsive formulations might be a promising clinical tool for the treatment of lung diseases such as coronavirus disease 2019 (COVID-19). It is encouraging that the use of lung ultrasound has been demonstrated to be an accurate imaging modality to detect pulmonary and pleural conditions [180]. Moreover, ultrasound imaging is a cost-effective, non-invasive diagnose tool. This method is especially suitable for pregnant women since it protects the fetus from radiation exposure [181]. Additionally, antiviral drugs or antigens can be encapsulated within polymerbased materials and be delivered to the lung site. Indeed, this concept could become a new potential platform for the clinical treatment and vaccine development of COVID-19.

(2) More biodegradable ultrasound-responsive polymeric materials should be developed. Compared to the lipidbased materials discussed elsewhere [182], polymerbased ultrasound-responsive materials may be more versatile drug delivery platforms. This is because these polymeric materials have a greater stability and, additionally, chemical modification can more easily be realized. However, ultrasound-responsive polymeric materials are still relatively underdeveloped in terms of drug delivery. Particularly, there are only a few studies regarding ultrasound-responsive polymer vesicles/ micelles; future efforts should be made for designing and developing such delivery vehicles. Encouragingly, in terms of biomedical applications, recent new insights show that block copolymer nanoparticles in metastable states can possess excellent ultrasound responsiveness [106]. This principle can be used in the design of ultrasound-responsive copolymer assemblies and might provide more options for the clinical translation of these polymeric nanomaterials.

(3) Future studies should be focused on enhancing the therapeutic effect and the development of a theranostic platform. For instance, incorporation of sonosensitizers to these ultrasound-responsive polymeric systems can further improve the therapeutic effect; this is also known as sonodynamic therapy [183-185]. In this treatment, sonosensitizers can be activated by low-intensity ultrasound irradiation and generate reactive oxygen species (ROS) to induce oxidative damage to targeted tumor cells [186-188]. Additionally, ultrasound is strongly attenuated by bone tissue. This further limits the ability of ultrasound imaging to provide physiologically specific functional information. For this reason, it is better to combine ultrasound-assisted drug delivery systems with other imaging modes, such as magnetic resonance imaging $[189,190]$ or photoacoustic imaging [191].

(4) Ultrasound-responsive materials have shown positive prospects in drug delivery; however, their safety should also be considered. For example, ultrasound waves can induce DNA damage that can lead to various cancer cell lines [192]. Therefore, more extensive preclinical studies are required to justify the use of ultrasound for treatment. Required preclinical analyses include genotoxicity, mutagenicity, carcinogenicity, and degradation assessments. Additionally, the parameters used for ultrasound exposure should be carefully optimized 


\section{a}
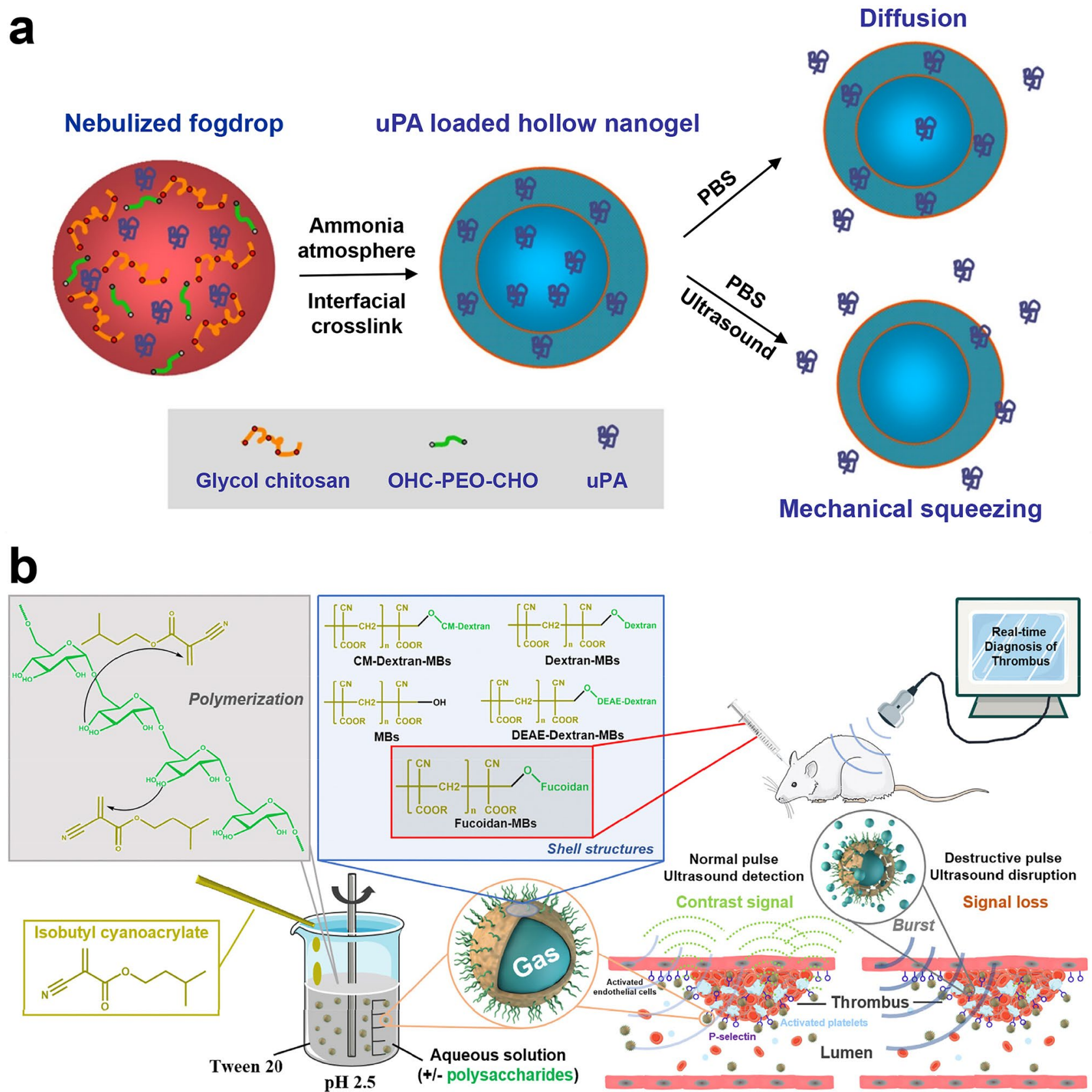

Fig. 5 Ultrasound-responsive polymeric carriers for the treatment of thrombotic diseases. a Synthesis of ultrasound-responsive uPAloaded hollow nanogels via ultrasonic spray technique. Reproduced with permission from [176]. b Overall schematic diagram of the one-

to maximize the drug release rate from ultrasoundresponsive polymeric carriers, while avoiding damage to healthy tissue.

To conclude, despite the recent developments in the design, synthesis, and application of ultrasound-responsive polymeric carriers, the bench-to-bedside translation is still under development. Future research should be focused on the step protocol for microbubble preparation and their subsequent use as molecular ultrasound contrast agent. Reproduced with permission from [179]

design of more advanced ultrasound-responsive polymerbased drug delivery systems, as well as the exploration of the interaction between these materials and living bodies.

Author contribution All authors contributed to the writing of this manuscript. 
Funding This project is supported by National Natural Science Foundation of China (21925505 and 21674081) and the China Postdoctoral Science Foundation (2020M671197). J.D. is a recipient of 5-year national science fund for distinguished young scholars.

\section{Declarations}

Competing interests The authors declare that they have no conflict of interest.

\section{References}

1. Zhang AT, Jung K, Li AH, Liu JQ, Boyer C. Recent advances in stimuli-responsive polymer systems for remotely controlled drug release. Prog Polym Sci. 2019;99:101164. https://doi.org/ 10.1016/j.progpolymsci.2019.101164.

2. Manouras T, Vamvakaki M. Field responsive materials: photo-, electro-, magnetic- and ultrasound-sensitive polymers. Polym Chem. 2017;8(1):74-96. https://doi.org/10.1039/c6py01455k.

3. Wheatley MA, Cochran M. Ultrasound contrast agents. J Drug Deliv Sci Technol. 2013;23(1):57-72. https://doi.org/10.1016/ s1773-2247(13)50007-4.

4. Li WP, Su CH, Chang YC, Lin YJ, Yeh CS. Ultrasoundinduced reactive oxygen species mediated therapy and imaging using a Fenton reaction activable polymersome. ACS Nano. 2016;10(2):2017-27. https://doi.org/10.1021/acsnano.5b06175.

5. Wood AKW, Ansaloni S, Ziemer LS, Lee WMF, Feldman MD, Sehgal CM. The antivascular action of physiotherapy ultrasound on murine tumors. Ultrasound Med Biol. 2005;31(10):1403-10. https://doi.org/10.1016/j.ultrasmedbio.2005.06.008.

6. Watson T. Ultrasound in contemporary physiotherapy practice. Ultrasonics. 2008;48(4):321-9. https://doi.org/10.1016/j.ultras. 2008.02.004.

7. Miller DL, Smith NB, Bailey MR, Czarnota GJ, Hynynen K, Makin IRS, et al. Overview of therapeutic ultrasound applications and safety considerations. J Ultrasound Med. 2012;31(4):623-34. https://doi.org/10.7863/jum.2012.31.4.623.

8. Kadam SU, Tiwari BK, Alvarez C, O'Donnell CP. Ultrasound applications for the extraction, identification and delivery of food proteins and bioactive peptides. Trends Food Sci Technol. 2015;46(1):60-7. https://doi.org/10.1016/j.tifs.2015.07.012.

9. Frazier N, Payne A, Dillon C, Subrahmanyam N, Ghandehari H. Enhanced efficacy of combination heat shock targeted polymer therapeutics with high intensity focused ultrasound. Nanomedicine. 2017;13(3):1235-43. https://doi.org/10.1016/j. nano.2016.11.014.

10. Frazier N, Payne A, de Bever J, Dillon C, Panda A, Subrahmanyam $\mathrm{N}$, et al. High intensity focused ultrasound hyperthermia for enhanced macromolecular delivery. J Control Release. 2016;241:186-93. https://doi.org/10.1016/j.jconrel.2016.09.030.

11. Ter Haar G, Coussios C. High intensity focused ultrasound: physical principles and devices. Int J Hyperthermia. 2007;23(2):89104. https://doi.org/10.1080/02656730601186138.

12. Coussios CC, Roy RA. Applications of acoustics and cavitation to noninvasive therapy and drug delivery. Annu Rev Fluid Mech. 2008;40:395-420. https://doi.org/10.1146/annurev.fluid. 40.111406.102116.

13. Mitragotri S. Innovation-healing sound: the use of ultrasound in drug delivery and other therapeutic applications. Nat Rev Drug Discov. 2005;4(3):255-60. https://doi.org/10.1038/nrd1662.

14. Ding CD, Tong L, Feng J, Fu JJ. Recent advances in stimuliresponsive release function drug delivery systems for tumor treatment. Molecules. 2016;21(12):1715. https://doi.org/10. 3390/molecules21121715.
15. Singh B, Khurana RK, Garg B, Saini S, Kaur R. Stimuliresponsive systems with diverse drug delivery and biomedical applications: recent updates and mechanistic pathways. Crit Rev Ther Drug Carrier Syst. 2017;34(3):209-55. https://doi. org/10.1615/CritRevTherDrugCarrierSyst.2017017284.

16. Zardad AZ, Choonara YE, du Toit LC, Kumar P, Mabrouk $\mathrm{M}$, Kondiah PPD, et al. A review of thermo- and ultrasoundresponsive polymeric systems for delivery of chemotherapeutic agents. Polymers. 2016;8(10):359. https://doi.org/10.3390/ polym 8100359 .

17. Pitt WG, Husseini GA, Staples BJ. Ultrasonic drug deliverya general review. Expert Opin Drug Deliv. 2004;1(1):37-56. https://doi.org/10.1517/17425247.1.1.37.

18. Cochran MC, Eisenbrey J, Ouma RO, Soulen M, Wheatley MA. Doxorubicin and paclitaxel loaded microbubbles for ultrasound triggered drug delivery. Int J Pharm. 2011;414(1-2):161-70. https://doi.org/10.1016/j.ijpharm.2011.05.030.

19. Hernandez C, Gulati S, Fioravanti G, Stewart PL, Exner AA. Cryo-EM visualization of lipid and polymer-stabilized perfluorocarbon gas nanobubbles-a step towards nanobubble mediated drug delivery. Sci Rep. 2017;7:13517. https://doi. org/10.1038/s41598-017-13741-1.

20. Shende PK, Desai D, Gaud RS. Role of solid-gas interface of nanobubbles for therapeutic applications. Crit Rev Ther Drug Carrier Syst. 2018;35(5):469-94. https://doi.org/10.1615/ CritRevTherDrugCarrierSyst.2018020229.

21. Shende P, Jain S. Polymeric nanodroplets: an emerging trend in gaseous delivery system. J Drug Targeting. 2019;27(10):103545. https://doi.org/10.1080/1061186x.2019.1588281.

22. Tang W, Yang Z, Wang S, Wang ZT, Song JB, Yu GC, et al. Organic semiconducting photoacoustic nanodroplets for laseractivatable ultrasound imaging and combinational cancer therapy. ACS Nano. 2018;12(3):2610-22. https://doi.org/10.1021/ acsnano.7b08628.

23. Rapoport N, Nam KH, Gupta R, Gao ZG, Mohan P, Payne A, et al. Ultrasound-mediated tumor imaging and nanotherapy using drug loaded, block copolymer stabilized perfluorocarbon nanoemulsions. J Control Release. 2011;153(1):4-15. https:// doi.org/10.1016/j.jconrel.2011.01.022.

24. Wei P, Sun M, Yang B, Xiao JG, Du JZ. Ultrasound-responsive polymersomes capable of endosomal escape for efficient cancer therapy. J Control Release. 2020;322:81-94. https://doi. org/10.1016/j.jconrel.2020.03.013.

25. Marin A, Muniruzzaman M, Rapoport N. Acoustic activation of drug delivery from polymeric micelles: effect of pulsed ultrasound. J Control Release. 2001;71(3):239-49. https://doi. org/10.1016/s0168-3659(01)00216-4.

26. Huebsch N, Kearney CJ, Zhao XH, Kim J, Cezar CA, Suo $\mathrm{ZG}$, et al. Ultrasound-triggered disruption and self-healing of reversibly cross-linked hydrogels for drug delivery and enhanced chemotherapy. Proc Natl Acad Sci USA. 2014;111(27):9762-7. https://doi.org/10.1073/pnas.1405469111.

27. Yamaguchi S, Higashi K, Azuma T, Okamoto A. Supramolecular polymeric hydrogels for ultrasound-guided protein release. Biotechnol J. 2019;14(5):1800530. https://doi.org/10.1002/ biot. 201800530.

28. Kuo JHS, Jan MS, Sung KC. Evaluation of the stability of polymerbased plasmid DNA delivery systems after ultrasound exposure. Int J Pharm. 2003;257(1-2):75-84. https://doi.org/10.1016/s03785173(03)00107-8.

29. Yin T, Wang P, Li J, Wang Y, Zheng B, Zheng R, et al. Tumorpenetrating codelivery of siRNA and paclitaxel with ultrasoundresponsive nanobubbles hetero-assembled from polymeric micelles and liposomes. Biomaterials. 2014;35(22):5932-43. https://doi.org/10.1016/j.biomaterials.2014.03.072. 
30. Aryal M, Arvanitis CD, Alexander PM, McDannold N. Ultrasoundmediated blood-brain barrier disruption for targeted drug delivery in the central nervous system. Adv Drug Deliv Rev. 2014;72:94-109. https://doi.org/10.1016/j.addr.2014.01.008.

31. Doukas AG, Kollias N. Transdermal drug delivery with a pressure wave. Adv Drug Deliv Rev. 2004;56(5):559-79. https://doi. org/10.1016/j.addr.2003.10.031.

32. Chung TW, Wang SS, Tsai WJ. Accelerating thrombolysis with chitosan-coated plasminogen activators encapsulated in poly-(lactide-co-glycolide) (PLGA) nanoparticles. Biomaterials. 2008;29(2):228-37. https://doi.org/10.1016/j.biomaterials. 2007.09.027.

33. Rapoport NY, Kennedy AM, Shea JE, Scaife CL, Nam KH. Controlled and targeted tumor chemotherapy by ultrasoundactivated nanoemulsions/microbubbles. J Control Release. 2009;138(3):268-76. https://doi.org/10.1016/j.jconrel. 2009.05.026.

34. Kamaly N, Yameen B, Wu J, Farokhzad OC. Degradable controlled-release polymers and polymeric nanoparticles: mechanisms of controlling drug release. Chem Rev. 2016;116(4):260263. https://doi.org/10.1021/acs.chemrev.5b00346.

35. Karimi M, Ghasemi A, Zangabad PS, Rahighi R, Basri SMM, Mirshekari H, et al. Smart micro/nanoparticles in stimulus-responsive drug/gene delivery systems. Chem Soc Rev. 2016;45(5):1457-501. https://doi.org/10.1039/c5cs00798d.

36. Dromi S, Frenkel V, Luk A, Traughber B, Angstadt M, Bur M, et al. Pulsed-high intensity focused ultrasound and low temperature sensitive liposomes for enhanced targeted drug delivery and antitumor effect. Clin Cancer Res. 2007;13(9):2722-7. https:// doi.org/10.1158/1078-0432.ccr-06-2443.

37. Schroeder A, Kost J, Barenholz Y. Ultrasound, liposomes, and drug delivery: principles for using ultrasound to control the release of drugs from liposomes. Chem Phys Lipids. 2009;162(12):1-16. https://doi.org/10.1016/j.chemphyslip.2009.08.003.

38. Grull H, Langereis S. Hyperthermia-triggered drug delivery from temperature-sensitive liposomes using MRI-guided high intensity focused ultrasound. J Control Release. 2012;161(2):317-27. https://doi.org/10.1016/j.jconrel.2012.04.041.

39. Ranjan A, Jacobs GC, Woods DL, Negussie AH, Partanen A, Yarmolenko PS, et al. Image-guided drug delivery with magnetic resonance guided high intensity focused ultrasound and temperature sensitive liposomes in a rabbit $\mathrm{V} \times 2$ tumor model. $\mathrm{J}$ Control Release. 2012;158(3):487-94. https://doi.org/10.1016/j. jconrel.2011.12.011.

40. Huang J, Xu JS, Xu RX. Heat-sensitive microbubbles for intraoperative assessment of cancer ablation margins. Biomaterials. 2010;31(6):1278-86. https://doi.org/10.1016/j.biomaterials. 2009.11.008.

41. Ahmed SE, Martins AM, Husseini GA. The use of ultrasound to release chemotherapeutic drugs from micelles and liposomes. J Drug Targeting. 2015;23(1):16-42. https://doi. org/10.3109/1061186x.2014.954119.

42. Zhou QL, Chen ZY, Wang YX, Yang F, Lin Y, Liao YY. Ultrasound-mediated local drug and gene delivery using nanocarriers. BioMed Res Int. 2014;2014:963891. https://doi. org/10.1155/2014/963891.

43. Bhatnagar S, Kwan JJ, Shah AR, Coussios C-C, Carlisle RC. Exploitation of sub-micron cavitation nuclei to enhance ultrasound-mediated transdermal transport and penetration of vaccines. J Control Release. 2016;238:22-30. https://doi.org/10.1016/j.jconrel.2016.07.016.

44. Frenkel V. Ultrasound mediated delivery of drugs and genes to solid tumors. Adv Drug Deliv Rev. 2008;60(10):1193-208. https:// doi.org/10.1016/j.addr.2008.03.007.

45. Plesset MS, Prosperetti A. Bubble dynamics and cavitation. Annu Rev Fluid Mech. 1977;9:145-85. https://doi.org/10.1146/ annurev.fl.09.010177.001045.
46. Lencioni R, Cioni D, Bartolozzi C. Tissue harmonic and contrastspecific imaging: back to gray scale in ultrasound. Eur Radiol. 2002;12(1):151-65. https://doi.org/10.1007/s003300101022.

47. Chung YE, Kim KW. Contrast-enhanced ultrasonography: advance and current status in abdominal imaging. Ultrasonography. 2015;34(1):3-18. https://doi.org/10.14366/usg.14034.

48. Tsutsui JM, Xie F, Porter RT. The use of microbubbles to target drug delivery. Cardiovasc Ultrasound. 2004;2:23. https://doi. org/10.1186/1476-7120-2-23.

49. Suslick KS, Price GJ. Applications of ultrasound to materials chemistry. Annu Rev Mater Sci. 1999;29:295-326. https://doi. org/10.1146/annurev.matsci.29.1.295.

50. Flint EB, Suslick KS. The temperature of cavitation. Science. 1991;253(5026):1397-9. https://doi.org/10.1126/science. 253.5026.1397.

51. Baker KG, Robertson VJ, Duck FA. A review of therapeutic ultrasound: biophysical effects. Phys Ther. 2001;81(7):1351-8. https://doi.org/10.1093/ptj/81.7.1351.

52. Sonis ST. Ultrasound-mediated drug delivery. Oral Dis. 2017;23(2):135-8. https://doi.org/10.1111/odi.12501.

53. Karshafian R, Bevan PD, Williams R, Samac S, Burns PN. Sonoporation by ultrasound-activated microbubble contrast agents: effect of acoustic exposure parameters on cell membrane permeability and cell viability. Ultrasound Med Biol. 2009;35(5):847-60. https://doi.org/10.1016/j.ultrasmedbio. 2008.10.013.

54. Husseini GA, Pitt WG. Micelles and nanoparticles for ultrasonic drug and gene delivery. Adv Drug Deliv Rev. 2008;60(10):113752. https://doi.org/10.1016/j.addr.2008.03.008.

55. Boucaud A. Trends in the use of ultrasound-mediated transdermal drug delivery. Drug Discov Today. 2004;9(19):827-8. https:// doi.org/10.1016/s1359-6446(04)03212-x.

56. Lavon A, Kost J. Ultrasound and transdermal drug delivery. Drug Discov Today. 2004;9(15):670-6. https://doi.org/10.1016/s13596446(04)03170-8.

57. Carpentier A, Canney M, Vignot A, Reina V, Beccaria K, Horodyckid C, et al. Clinical trial of blood-brain barrier disruption by pulsed ultrasound. Sci Transl Med. 2016;8(343):343re2. https://doi. org/10.1126/scitranslmed.aaf6086.

58. Sun T, Zhang YZ, Power C, Alexander PM, Sutton JT, Aryal $\mathrm{M}$, et al. Closed-loop control of targeted ultrasound drug delivery across the blood-brain/tumor barriers in a rat glioma model. Proc Natl Acad Sci USA. 2017;114(48):E10281-90. https://doi. org/10.1073/pnas.1713328114.

59. O'Reilly MA, Hynynen K. Blood-brain barrier: real-time feedback-controlled focused ultrasound disruption by using an acoustic emissions-based controller. Radiology. 2012;263(1):96-106. https://doi.org/10.1148/radiol.11111417.

60. Dasgupta A, Liu M, Ojha T, Storm G, Kiessling F, Lammers T. Ultrasound-mediated drug delivery to the brain: principles, progress and prospects. Drug Discov Today Technol. 2016;20:41-8. https://doi.org/10.1016/j.ddtec.2016.07.007.

61. Ferrara K, Pollard R, Borden M. Ultrasound microbubble contrast agents: fundamentals and application to gene and drug delivery. Annu Rev Biomed Eng. 2007;9:415-47. https://doi. org/10.1146/annurev.bioeng.8.061505.095852.

62. Kabalnov A, Klein D, Pelura T, Schutt E, Weers J. Dissolution of multicomponent microbubbles in the bloodstream: 1 Theory. Ultrasound Med Biol. 1998;24(5):739-49. https://doi. org/10.1016/s0301-5629(98)00034-9.

63. Grinstaff MW, Suslick KS. Air-filled proteinaceous microbubblessynthesis of an echo-contrast agent. Proc Natl Acad Sci USA. 1991;88(17):7708-10. https://doi.org/10.1073/pnas.88.17.7708.

64. Xiong XY, Zhao FL, Shi MR, Yang H, Liu YY. Polymeric microbubbles for ultrasonic molecular imaging and targeted 
therapeutics. J Biomater Sci Polym Ed. 2011;22(4-6):417-28. https://doi.org/10.1163/092050610x540440.

65. Pisani E, Tsapis N, Paris J, Nicolas V, Cattel L, Fattal E. Polymeric nano/microcapsules of liquid perfluorocarbons for ultrasonic imaging: physical characterization. Langmuir. 2006;22(9):4397-402. https://doi.org/10.1021/la0601455.

66. Hoff L, Sontum PC, Hovem JM. Oscillations of polymeric microbubbles: effect of the encapsulating shell. J Acoust Soc Am. 2000;107(4):2272-80. https://doi.org/10.1121/1.428557.

67. Yang F, Li YX, Chen ZP, Gu N. The preparation and application of microbubble contrast agent combining ultrasound imaging and magnetic resonance imaging. Chin Sci Bull. 2009;54(17):29349. https://doi.org/10.1007/s11434-009-0168-5.

68. Wheatley MA, Lathia JD, Oum KL. Polymeric ultrasound contrast agents targeted to integrins: importance of process methods and surface density of ligands. Biomacromol. 2007;8(2):516-22. https://doi.org/10.1021/bm060659i.

69. Niu CC, Wang ZG, Lu GM, Krupka TM, Sun Y, You YF, et al. Doxorubicin loaded superparamagnetic PLGA-iron oxide multifunctional microbubbles for dual-mode US/MR imaging and therapy of metastasis in lymph nodes. Biomaterials. 2013;34(9):230717. https://doi.org/10.1016/j.biomaterials.2012.12.003.

70. Jablonowski LJ, Teraphongphom NT, Wheatley MA. Drug delivery from a multi-faceted ultrasound contrast agent: influence of shell composition. Mol Pharmaceutics. 2017;14(10):3448-56. https://doi.org/10.1021/acs.molpharmaceut.7b00451.

71. Eisenbrey JR, Burstein OM, Kambhampati R, Forsberg F, Liu JB, Wheatley MA. Development and optimization of a doxorubicin loaded poly(lactic acid) contrast agent for ultrasound directed drug delivery. J Control Release. 2010;143(1):38-44. https://doi. org/10.1016/j.jconrel.2009.12.021.

72. McEwan C, Fowley C, Nomikou N, McCaughan B, McHale AP, Callan JF. Polymeric microbubbles as delivery vehicles for sensitizers in sonodynamic therapy. Langmuir. 2014;30(49):1492630. https://doi.org/10.1021/la503929c.

73. Cochran MC, Eisenbrey JR, Soulen MC, Schultz SM, Ouma RO, White SB, et al. Disposition of ultrasound sensitive polymeric drug carrier in a rat hepatocellular carcinoma model. Acad Radiol. 2011;18(11):1341-8. https://doi.org/10.1016/j.acra.2011.06.013.

74. Lentacker I, De Geest BG, Vandenbroucke RE, Peeters L, Demeester J, De Smedt SC, et al. Ultrasound-responsive polymercoated microbubbles that bind and protect DNA. Langmuir. 2006;22(17):7273-8. https://doi.org/10.1021/la0603828.

75. Kooiman K, Bohmer MR, Emmer M, Vos HJ, Chlon C, Shi WT, et al. Oil-filled polymer microcapsules for ultrasound-mediated delivery of lipophilic drugs. J Control Release. 2009;133(2):10918. https://doi.org/10.1016/j.jconrel.2008.09.085.

76. Villa R, Cerroni B, Vigano L, Margheritelli S, Abolafio G, Oddo $\mathrm{L}$, et al. Targeted doxorubicin delivery by chitosan-galactosylated modified polymer microbubbles to hepatocarcinoma cells. Colloids Surf B. 2013;110:434-42. https://doi.org/10.1016/j.colsurfb. 2013.04.022.

77. Lensen D, Gelderblom EC, Vriezema DM, Marmottant P, Verdonschot N, Versluis M, et al. Biodegradable polymeric microcapsules for selective ultrasound-triggered drug release. Soft Matter. 2011;7(11):5417-22. https://doi.org/10.1039/c1sm05324h.

78. Zhao YZ, Du LN, Lu CT, Jin YG, Ge SP. Potential and problems in ultrasound-responsive drug delivery systems. Int J Nanomed. 2013;8:1621-33. https://doi.org/10.2147/ijn.s43589.

79. Cavalieri F, Zhou MF, Tortora M, Lucilla B, Ashokkumar M. Methods of preparation of multifunctional microbubbles and their in vitro/in vivo assessment of stability, functional and structural properties. Curr Pharm Des. 2012;18(15):2135-51. https:// doi.org/10.2174/138161212800099874.

80. Pasqualini R, Arap W, McDonald DM. Probing the structural and molecular diversity of tumor vasculature. Trends Mol Med.
2002;8(12):563-71. https://doi.org/10.1016/s1471-4914(02) 02429-2.

81. Li WW. Tumor angiogenesis: molecular pathology, therapeutic targeting, and imaging. Acad Radiol. 2000;7(10):800-11. https:// doi.org/10.1016/s1076-6332(00)80629-7.

82. Wickline SA, Lanza GM. Molecular imaging, targeted therapeutics, and nanoscience. J Cell Biochem. 2002;39:90-7. https://doi. org/10.1002/jcb.10422.

83. Brotchie A, Zhang XH. Response of interfacial nanobubbles to ultrasound irradiation. Soft Matter. 2011;7(1):265-9. https://doi. org/10.1039/c0sm00731e.

84. Wang Y, Li X, Zhou Y, Huang PY, Xu YH. Preparation of nanobubbles for ultrasound imaging and intracelluar drug delivery. Int J Pharm. 2010;384(1-2):148-53. https://doi.org/10.1016/j. ijpharm.2009.09.027.

85. Cavalli R, Bisazza A, Rolfo A, Balbis S, Madonnaripa D, Caniggia I, et al. Ultrasound-mediated oxygen delivery from chitosan nanobubbles. Int J Pharm. 2009;378(1-2):215-7. https://doi. org/10.1016/j.ijpharm.2009.05.058.

86. Baghbani F, Mortarzadeh F, Mohandesi JA, Yazdian F, Mokhtari-Dizaji M. Novel alginate-stabilized doxorubicinloaded nanodroplets for ultrasounic theranosis of breast cancer. Int J Biol Macromol. 2016;93:512-9. https://doi.org/10.1016/j. ijbiomac.2016.09.008.

87. Gao D, Gao JB, Xu M, Cao Z, Zhou LY, Li YQ, et al. Targeted ultrasound-triggered phase transition nanodroplets for Her2overexpressing breast cancer diagnosis and gene transfection. Mol Pharmaceutics. 2017;14(4):984-98. https://doi.org/10.1021/ acs.molpharmaceut.6b00761.

88. Gao JB, Yu BQ, Li C, Xu M, Cao Z, Xie XY, et al. Ultrasound triggered phase-change nanodroplets for doxorubicin prodrug delivery and ultrasound diagnosis: an in vitro study. Colloids Surf B. 2019;174:416-25. https://doi.org/10.1016/j.colsurfb. 2018.11.046.

89. Mannaris C, Yang CX, Carugo D, Owen J, Lee JY, Nwokeoha $\mathrm{S}$, et al. Acoustically responsive polydopamine nanodroplets: a novel theranostic agent. Ultrason Sonochem. 2020;60:104782. https://doi.org/10.1016/j.ultsonch.2019.104782.

90. Wu HP, Rognin NG, Krupka TM, Solorio L, Yoshiara H, Guenette $\mathrm{G}$, et al. Acoustic characterization and pharmacokinetic analyses of new nanobubble ultrasound contrast agents. Ultrasound Med Biol. 2013;39(11):2137-46. https://doi.org/10.1016/j.ultrasmedbio. 2013.05.007.

91. Gao Y, Hernandez C, Yuan HX, Lilly J, Kota P, Zhou HY, et al. Ultrasound molecular imaging of ovarian cancer with CA-125 targeted nanobubble contrast agents. Nanomedicine. 2017;13(7):2159-68. https://doi.org/10.1016/j. nano.2017.06.001.

92. Nittayacharn P, Yuan HX, Hernandez C, Bielecki P, Zhou HY, Exner AA. Enhancing tumor drug distribution with ultrasoundtriggered nanobubbles. J Pharm Sci. 2019;108(9):3091-8. https:// doi.org/10.1016/j.xphs.2019.05.004.

93. Cavalli R, Bisazza A, Trotta M, Argenziano M, Civra A, Donalisio $M$, et al. New chitosan nanobubbles for ultrasound-mediated gene delivery: preparation and in vitro characterization. Int $\mathrm{J}$ Nanomed. 2012;7:3309-18. https://doi.org/10.2147/ijn.s30912.

94. Silva EK, Rosa M, Meireles MAA. Ultrasound-assisted formation of emulsions stabilized by biopolymers. Curr Opin Food Sci. 2015;5:50-9. https://doi.org/10.1016/j.cofs.2015.08.007.

95. Li DS, Yoon SJ, Pelivanov I, Frenz M, O’Donnell M, Pozzo LD. Polypyrrole-coated perfluorocarbon nanoemulsions as a sonophotoacoustic contrast agent. Nano Lett. 2017;17(10):6184-94. https://doi.org/10.1021/acs.nanolett.7b02845.

96. Zhong Q, Yoon BC, Aryal M, Wang JB, Ilovitsh T, Baikoghli $\mathrm{MA}$, et al. Polymeric perfluorocarbon nanoemulsions are ultrasound-activated wireless drug infusion catheters. 
Biomaterials. 2019;206:73-86. https://doi.org/10.1016/j. biomaterials.2019.03.021.

97. Du JZ, O'Reilly RK. Advances and challenges in smart and functional polymer vesicles. Soft Matter. 2009;5(19):3544-61. https:// doi.org/10.1039/b905635a.

98. Chen S, Qin JL, Du JZ. Two principles for polymersomes with ultrahigh biomacromolecular loading efficiencies: acid-induced adsorption and affinity-enhanced attraction. Macromolecules. 2020;53(10):3978-93. https://doi.org/10.1021/acs.macromol. $0 \mathrm{c} 00252$.

99. Cornel EJ, Jiang JH, Chen S, Du JZ. Principles and characteristics of polymerization-induced self-assembly with various polymerization techniques. CCS Chem. 2020;2:2104-25. https:// doi.org/10.31635/ccschem.020.202000470.

100. Chen S, Lin S, Xi YJ, Xiao YF, Du JZ. Polymersomes with inhomogeneous membranes, asymmetrical coronas and fused membranes and coronas. Chin Sci Bull. 2020;65(24):2615-26. https:// doi.org/10.1360/TB-2020-0472.

101. Liu DQ, Sun H, Xiao YF, Chen S, Cornel EJ, Zhu YQ, et al. Design principles, synthesis and biomedical applications of polymer vesicles with inhomogeneous membranes. J Control Release. 2020;326:365-86. https://doi.org/10.1016/j.jconrel.2020.07.018.

102. Zhu YQ, Yang B, Chen S, Du JZ. Polymer vesicles: mechanism, preparation, application, and responsive behavior. Prog Polym Sci. 2017;64:1-22. https://doi.org/10.1016/j.progpolymsci. 2015.05.001.

103. Liu QM, Song LW, Chen S, Gao JY, Zhao PY, Du JZ. A superparamagnetic polymersome with extremely high $\mathrm{T}_{2}$ relaxivity for MRI and cancer-targeted drug delivery. Biomaterials. 2017;114:23-33. https://doi.org/10.1016/j.biomaterials. 2016.10.027.

104. Liu QM, Chen S, Chen J, Du JZ. An asymmetrical polymer vesicle strategy for significantly improving $\mathrm{T}_{1}$ MRI sensitivity and cancer-targeted drug delivery. Macromolecules. 2015;48(3):739_ 49. https://doi.org/10.1021/ma502255s.

105. Chen WQ, Du JZ. Ultrasound and $\mathrm{pH}$ dually responsive polymer vesicles for anticancer drug delivery. Sci Rep. 2013;3:2162. https:// doi.org/10.1038/srep02162.

106. Yang B, Du JZ. On the origin and regulation of ultrasound responsiveness of block copolymer nanoparticles. Sci China Chem. 2020;63(2):272-81. https://doi.org/10.1007/s11426019-9612-8

107. Yang B, Du JZ. Ultrasound-responsive homopolymer nanoparticles. Chin J Polym Sci. 2020;38(4):349-56. https://doi.org/ 10.1007/s10118-020-2345-6.

108. Huang L, Yu CH, Huang T, Xu ST, Bai YP, Zhou YF. Ultrasoundresponsive ultrathin multiblock copolyamide vesicles. Nanoscale. 2016;8(9):4922-6. https://doi.org/10.1039/c5nr08596a.

109. Wang J, Pelletier M, Zhang HJ, Xia HS, Zhao Y. High-frequency ultrasound-responsive block copolymer micelle. Langmuir. 2009;25(22):13201-5. https://doi.org/10.1021/la9018794.

110. Xuan J, Boissiere O, Zhao Y, Yan B, Tremblay L, Lacelle S, et al. Ultrasound-responsive block copolymer micelles based on a new amplification mechanism. Langmuir. 2012;28(47):16463-8. https:// doi.org/10.1021/la303946b.

111. Li YW, Tong R, Xia HS, Zhang HJ, Xuan JA. High intensity focused ultrasound and redox dual responsive polymer micelles. Chem Commun. 2010;46(41):7739-41. https://doi.org/10.1039/ c0cc02628j.

112. Tong R, Lu XL, Xia HS. A facile mechanophore functionalization of an amphiphilic block copolymer towards remote ultrasound and redox dual stimulus responsiveness. Chem Commun. 2014;50(27):3575-8. https://doi.org/10.1039/c4cc00103f.

113. Tomatsu I, Peng K, Kros A. Photoresponsive hydrogels for biomedical applications. Adv Drug Delivery Rev. 2011;63(1415):1257-66. https://doi.org/10.1016/j.addr.2011.06.009.
114. El-Sherbiny I, Khalil I, Ali I, Yacoub M. Updates on smart polymeric carrier systems for protein delivery. Drug Dev Ind Pharm. 2017;43(10):1567-83. https://doi.org/10.1080/03639045. 2017.1338723.

115. Minh Khanh N, Alsberg E. Bioactive factor delivery strategies from engineered polymer hydrogels for therapeutic medicine. Prog Polym Sci. 2014;39(7):1235-65. https://doi.org/10.1016/j. progpolymsci.2013.12.001.

116. Alford A, Tucker B, Kozlovskaya V, Chen J, Gupta N, Caviedes R, et al. Encapsulation and ultrasound-triggered release of G-quadruplex DNA in multilayer hydrogel microcapsules. Polymers. 2018;10(12):1342. https://doi.org/10.3390/polym10121342.

117. Morch Y, Hansen R, Berg S, Aslund AKO, Glomm WR, Eggen $\mathrm{S}$, et al. Nanoparticle-stabilized microbubbles for multimodal imaging and drug delivery. Contrast Media Mol Imaging. 2015;10(5):356-66. https://doi.org/10.1002/cmmi.1639.

118. Li YQ, Liu RQ, Liu LW, Zhang Y, Sun J, Ma PZ, et al. Study on phase transition and contrast-enhanced imaging of ultrasoundresponsive nanodroplets with polymer shells. Colloids Surf B. 2020;189:110849. https://doi.org/10.1016/j.colsurfb.2020.110849.

119. Pangu GD, Davis KP, Bates FS, Hammer DA. Ultrasonically induced release from nanosized polymer vesicles. Macromol Biosci. 2010;10(5):546-54. https://doi.org/10.1002/mabi.201000081.

120. Liang B, Tong R, Wang ZH, Guo SW, Xia HS. High intensity focused ultrasound responsive metallo-supramolecular block copolymer micelles. Langmuir. 2014;30(31):9524-32. https:// doi.org/10.1021/la500841x.

121. Chandan R, Mehta S, Banerjee R. Ultrasound-responsive carriers for therapeutic applications. ACS Biomater Sci Eng. 2020;6(9):4731-47. https://doi.org/10.1021/acsbiomaterials. $9 \mathrm{~b} 01979$.

122. Duan L, Yang F, He W, Song LN, Qiu F, Xu N, et al. A multigradient targeting drug delivery system based on RGD-L-TRAILlabeled magnetic microbubbles for cancer theranostics. Adv Funct Mater. 2016;26(45):8313-24. https://doi.org/10.1002/adfm. 201603637

123. Kulkarni P, Haldar MK, Karandish F, Confeld M, Hossain R, Borowicz P, et al. Tissue-penetrating, hypoxia-responsive echogenic polymersomes for drug delivery to solid tumors. ChemEur J. 2018;24(48):12490-4. https://doi.org/10.1002/chem. 201802229

124. Di Ianni T, Bose RJC, Sukumar UK, Bachawal S, Wang HJ, Telichko A, et al. Ultrasound/microbubble-mediated targeted delivery of anticancer microrna-loaded nanoparticles to deep tissues in pigs. J Control Release. 2019;309:1-10. https://doi. org/10.1016/j.jconrel.2019.07.024.

125. Lin LZ, Fan Y, Gao F, Jin LF, Li D, Sun WJ, et al. UTMD-promoted co-delivery of gemcitabine and miR-21 inhibitor by dendrimerentrapped gold nanoparticles for pancreatic cancer therapy. Theranostics. 2018;8(7):1923-39. https://doi.org/10.7150/thno.22834.

126. Chowdhury SM, Lee T, Willmann JK. Ultrasound-guided drug delivery in cancer. Ultrasonography. 2017;36(3):171-84. https:// doi.org/10.14366/usg.17021.

127. Ferrara KW. Driving delivery vehicles with ultrasound. Adv Drug Deliv Rev. 2008;60(10):1097-102. https://doi.org/10.1016/j. addr.2008.03.002.

128. Bohmer MR, Klibanov AL, Tiemann K, Hall CS, Gruell H, Steinbach OC. Ultrasound triggered image-guided drug delivery. Eur J Radiol. 2009;70(2):242-53. https://doi.org/10.1016/j.ejrad. 2009.01.051.

129. Zhang L, Yin TH, Li B, Zheng RQ, Qiu C, Lam KS, et al. Sizemodulable nanoprobe for high-performance ultrasound imaging and drug delivery against cancer. ACS Nano. 2018;12(4):344960. https://doi.org/10.1021/acsnano.8b00076.

130. Wu PY, Jia YL, Qu F, Sun Y, Wang P, Zhang K, et al. Ultrasoundresponsive polymeric micelles for sonoporation-assisted 
site-specific therapeutic action. ACS Appl Mater Interfaces. 2017;9(31):25706-16. https://doi.org/10.1021/acsami.7b05469.

131. Yu M, Xu XL, Cai YJ, Zou LY, Shuai XT. Perfluorohexanecored nanodroplets for stimulations-responsive ultrasonography and $\mathrm{O}_{2}$-potentiated photodynamic therapy. Biomaterials. 2018;175:61-71. https://doi.org/10.1016/j.biomaterials. 2018.05.019.

132. Zhu JJ, Wang Z, Xu XL, Xu M, Yang X, Zhang CY, et al. Polydopamine-encapsulated perfluorocarbon for ultrasound contrast imaging and photothermal therapy. Mol Pharmaceutics. 2019;17(3):817-26. https://doi.org/10.1021/acs.molpharmaceut. 9b01070.

133. Wang YR, Yin TH, Su ZW, Qiu C, Wang Y, Zheng RQ, et al. Highly uniform ultrasound-sensitive nanospheres produced by a $\mathrm{pH}$-induced micelle-to-vesicle transition for tumor-targeted drug delivery. Nano Res. 2018;11(7):3710-21. https://doi. org/10.1007/s12274-017-1939-y.

134. Tsou YH, Zhang XQ, Zhu H, Syed S, Xu XY. Drug delivery to the brain across the blood-brain barrier using nanomaterials. Small. 2017;13(43):1701921. https://doi.org/10.1002/smll.201701921.

135. Abbott NJ, Ronnback L, Hansson E. Astrocyte-endothelial interactions at the blood-brain barrier. Nat Rev Neurosci. 2006;7(1):41-53. https://doi.org/10.1038/nrn1824.

136. Valdez MA, Fernandez E, Matsunaga T, Erickson RP, Trouard TP. Distribution and diffusion of macromolecule delivery to the brain via focused ultrasound using magnetic resonance and multispectral fluorescence imaging. Ultrasound Med Biol. 2020;46(1):122-36. https://doi.org/10.1016/j.ultrasmedbio. 2019.08.024.

137. Vykhodtseva N, McDannold N, Hynynen K. Progress and problems in the application of focused ultrasound for blood-brain barrier disruption. Ultrasonics. 2008;48(4):279-96. https://doi. org/10.1016/j.ultras.2008.04.004.

138. Fan $\mathrm{CH}$, Ting CY, Lin HJ, Wang CH, Liu HL, Yen TC, et al. SPIO-conjugated, doxorubicin-loaded microbubbles for concurrent MRI and focused-ultrasound enhanced brain-tumor drug delivery. Biomaterials. 2013;34(14):3706-15. https://doi. org/10.1016/j.biomaterials.2013.01.099.

139. Lammers T, Koczera P, Fokong S, Gremse F, Ehling J, Vogt M, et al. Theranostic uspio-loaded microbubbles for mediating and monitoring blood-brain barrier permeation. Adv Funct Mater. 2015;25(1):36-43. https://doi.org/10.1002/adfm.201401199.

140. Ting CY, Fan CH, Liu HL, Huang CY, Hsieh HY, Yen TC, et al. Concurrent blood-brain barrier opening and local drug delivery using drug-carrying microbubbles and focused ultrasound for brain glioma treatment. Biomaterials. 2012;33(2):704-12. https:// doi.org/10.1016/j.biomaterials.2011.09.096.

141. Raymond SB, Treat LH, Dewey JD, McDannold NJ, Hynynen K, Bacskai BJ. Ultrasound enhanced delivery of molecular imaging and therapeutic agents in Alzheimer's disease mouse models. PLoS ONE. 2008;3(5):e2175. https://doi.org/10.1371/journal. pone. 0002175 .

142. Aslund AKO, Berg S, Hak S, Morch Y, Torp SH, Sandvig A, et al. Nanoparticle delivery to the brain-by focused ultrasound and self-assembled nanoparticle-stabilized microbubbles. J Control Release. 2015;220:287-94. https://doi. org/10.1016/j.jconrel.2015.10.047.

143. Chen CC, Sheeran PS, Wu S-Y, Olumolade OO, Dayton PA, Konofagou EE. Targeted drug delivery with focused ultrasoundinduced blood-brain barrier opening using acousticallyactivated nanodroplets. J Control Release. 2013;172(3):795804. https://doi.org/10.1016/j.jconrel.2013.09.025.

144. Zhang X, Hu JG, Zhao GJ, Huang N, Tan Y, Pi L, et al. PEGylated PLGA-based phase shift nanodroplets combined with focused ultrasound for blood brain barrier opening in rats.
Oncotarget. 2017;8(24):38927-36. https://doi.org/10.18632/ oncotarget. 17155 .

145. Henriquez-Camacho C, Garcia-Casasola G, Guillen-Astete C, Losa J. Ultrasound for the diagnosis of infectious diseases: approach to the patient at point of care and at secondary level. J Infect. 2015;71(1):1-8. https://doi.org/10.1016/j. jinf.2015.03.003.

146. Brunetti E, Heller T, Richter J, Kaminstein D, Youkee D, Giordani MT, et al. Application of ultrasonography in the diagnosis of infectious diseases in resource-limited settings. Curr Infect Dis Rep. 2016;18(2):6. https://doi.org/10.1007/ s11908-015-0512-7.

147. Revzin MV, Moshiri M, Bokhari J, Pellerito JS, Menias C. Sonographic assessment of infectious diseases of the gastrointestinal tract: from scanning to diagnosis. Abdom Radiol. 2020;45(2):261-92. https://doi.org/10.1007/s00261-019-02358-9.

148. Liu J, Liu F, Liu Y, Wang H-W, Feng Z-C. Lung ultrasonography for the diagnosis of severe neonatal pneumonia. Chest. 2014;146(2):383-8. https://doi.org/10.1378/chest.13-2852.

149. Gerber S, Hohlfeld P. Screening for infectious diseases. Childs Nerv Syst. 2003;19(7-8):429-32. https://doi.org/10.1007/ s00381-003-0766-5.

150. Dong Y, Chen S, Wang Z, Peng N, Yu J. Synergy of ultrasound microbubbles and vancomycin against staphylococcus epidermidis biofilm. J Antimicrob Chemother. 2013;68(4):816-26. https://doi.org/10.1093/jac/dks490.

151. Ma X, Pan H, Wu G, Yang Z, Yi J. Ultrasound may be exploited for the treatment of microbial diseases. Med Hypotheses. 2009;73(1):18-9. https://doi.org/10.1016/j.mehy.2009.01.033.

152. Norris P, Noble M, Francolini I, Vinogradov AM, Stewart PS, Ratner BD, et al. Ultrasonically controlled release of ciprofloxacin from self-assembled coatings on poly(2-hydroxyethyl methacrylate) hydrogels for pseudomonas aeruginosa biofilm prevention. Antimicrob Agents Chemother. 2005;49(10):42729. https://doi.org/10.1128/aac.49.10.4272-4279.2005.

153. Gondim BLC, Catarino JD, de Sousa MAD, Silva MD, Lemes MR, de Carvalho-Costa TM, et al. Nanoparticle-mediated drug delivery: blood-brain barrier as the main obstacle to treating infectious diseases in cns. Curr Pharm Des. 2019;25(37):398396. https://doi.org/10.2174/1381612825666191014171354.

154. Tosi G, Costantino L, Ruozi B, Forni F, Vandelli MA. Polymeric nanoparticles for the drug delivery to the central nervous system. Expert Opin Drug Deliv. 2008;5(2):155-74. https:// doi.org/10.1517/17425247.5.2.155.

155. Polat BE, Hart D, Langer R, Blankschtein D. Ultrasoundmediated transdermal drug delivery: mechanisms, scope, and emerging trends. J Control Release. 2011;152(3):330-48. https:// doi.org/10.1016/j.jconrel.2011.01.006.

156. Alexander A, Dwivedi S, Ajazuddin, Giri TK, Saraf S, Saraf S, et al. Approaches for breaking the barriers of drug permeation through transdermal drug delivery. J Control Release. 2012;164(1):26-40. https://doi.org/10.1016/j.jconrel. 2012.09.017.

157. Mitragotri S, Kost J. Low-frequency sonophoresis-a review. Adv Drug Deliv Rev. 2004;56(5):589-601. https://doi. org/10.1016/j.addr.2003.10.024.

158. Tachibana K. Transdermal delivery of insulin to alloxandiabetic rabbits by ultrasound exposure. Pharm Res. 1992;9(7):952-4. https://doi.org/10.1023/a:1015869420159.

159. Tachibana K, Tachibana S. Use of ultrasound to enhance the local-anesthetic effect of topically applied aqueous lidocaine. Anesthesiology. 1993;78(6):1091-6. https://doi. org/10.1097/00000542-199306000-00011.

160. Mitragotri S, Blankschtein D, Langer R. Ultrasound-mediated transdermal protein delivery. Science. 1995;269(5225):850-3. https://doi.org/10.1126/science.7638603. 
161. Huang D, Sun M, Bu Y, Luo F, Lin C, Lin Z, et al. Microcapsuleembedded hydrogel patches for ultrasound responsive and enhanced transdermal delivery of diclofenac sodium. J Mater Chem B. 2019;7(14):2330-7. https://doi.org/10.1039/ c8tb02928h.

162. Sciurti E, Primavera R, Di Mascolo D, Rizzo A, Balena A, Padmanabhan SK, et al. Ultrasound-induced deformation of PLGA-microplates for on-command drug release. Microelectron Eng. 2020;229:111360. https://doi.org/10.1016/j. mee.2020.111360.

163. Jin X, Zhu DD, Chen BZ, Ashfaq M, Guo XD. Insulin delivery systems combined with microneedle technology. Adv Drug Deliv Rev. 2018;127:119-37. https://doi.org/10.1016/j.addr.2018.03.011.

164. Zhou XW, Luo ZM, Baidya A, Kim HJ, Wang CR, Jiang X, et al. Biodegradable beta-cyclodextrin conjugated gelatin methacryloyl microneedle for delivery of water-insoluble drug. Adv Healthcare Mater. 2020;9(11):2000527. https://doi.org/10.1002/adhm. 202000527.

165. Li W, Tang J, Terry RN, Li S, Brunie A, Callahan RL, et al. Long-acting reversible contraception by effervescent microneedle patch. Sci Adv. 2019;5(11):eaaw8145. https://doi.org/10.1126/ sciadv.aaw8145.

166. Chen BZ, Zhang LQ, Xia YY, Zhang XP, Guo XD. A basal-bolus insulin regimen integrated microneedle patch for intraday postprandial glucose control. Sci Adv. 2020;6(28):eaba7260. https:// doi.org/10.1126/sciadv.aba7260.

167. Petrilli R, Vianna Lopez RF. Physical methods for topical skin drug delivery: concepts and applications. Braz J Pharm Sci. 2018;54:e01008. https://doi.org/10.1590/s2175-97902018000001008.

168. Cross SE, Roberts MS. Physical enhancement of transdermal drug application: is delivery technology keeping up with pharmaceutical development? Curr Drug Deliv. 2004;1(1):81-92. https:// doi.org/10.2174/1567201043480045.

169. Ryu YC, Kim DI, Kim SH, Wang H-MD, Hwang BH. Synergistic transdermal delivery of biomacromolecules using sonophoresis after microneedle treatment. Biotechnol Bioprocess Eng. 2018;23(3):286-92. https://doi.org/10.1007/s12257-018-0070-6.

170. Bok M, Zhao Z-J, Jeon S, Jeong J-H, Lim E. Ultrasonically and iontophoretically enhanced drug-delivery system based on dissolving microneedle patches. Sci Rep. 2020;10(1):2027. https:// doi.org/10.1038/s41598-020-58822-w.

171. de St VM, Crake C, Coussios CC, Stride E. Properties, characteristics and applications of microbubbles for sonothrombolysis. Expert Opin Drug Deliv. 2014;11(2):187-209. https://doi. org/10.1517/17425247.2014.868434.

172. Varna M, Juenet M, Bayles R, Mazighi M, Chauvierre C, Letourneur D. Nanomedicine as a strategy to fight thrombotic diseases. Futur Sci OA. 2015;1(4):Fso46. https://doi.org/10.4155/fso.15.46.

173. Huang T, Li N, Gao JQ. Recent strategies on targeted delivery of thrombolytics. Asian J Pharm Sci. 2019;14(3):233-47. https:// doi.org/10.1016/j.ajps.2018.12.004.

174. Victor MD, Barnsley LC, Carugo D, Owen J, Coussios CC, Stride E. Sonothrombolysis with magnetically targeted microbubbles. Ultrasound Med Biol. 2019;45(5):1151-63. https://doi. org/10.1016/j.ultrasmedbio.2018.12.014.

175. Uesugi Y, Kawata H, Jo J-i, Saito Y, Tabata Y. An ultrasoundresponsive nano delivery system of tissue-type plasminogen activator for thrombolytic therapy. J Control Release. 2010;147(2):26977. https://doi.org/10.1016/j.jconrel.2010.07.127.

176. Jin HQ, Tan H, Zhao LL, Sun WP, Zhu LJ, Sun YG, et al. Ultrasoundtriggered thrombolysis using urokinase-loaded nanogels. Int $\mathbf{J}$ Pharm. 2012;434(1-2):384-90. https://doi.org/10.1016/j.jpharm. 2012.06.001.
177. Haber E, Quertermous T, Matsueda GR, Runge MS. Innovative approaches to plasminogen-activator therapy. Science. 1989;243(4887):51-6. https://doi.org/10.1126/science.2492113.

178. Holden RW. Plasminogen activators: pharmacology and therapy. Radiology. 1990;174(3):993-1001. https://doi.org/10.1148/radiology. 174.3.174-3-993.

179. Li B, Aid-Launais R, Labour MN, Zenych A, Juenet M, Choqueux $\mathrm{C}$, et al. Functionalized polymer microbubbles as new molecular ultrasound contrast agent to target P-selectin in thrombus. Biomaterials. 2019;194:139-50. https://doi.org/10.1016/j. biomaterials.2018.12.023.

180. Pata D, Valentini P, De Rose C, De Santis R, Morello R, Buonsenso D. Chest computed tomography and lung ultrasound findings in COVID-19 pneumonia: a pocket review for non-radiologists. Front Med. 2020;7:375. https://doi.org/10.3389/fmed.2020.00375.

181. Inchingolo R, Smargiassi A, Moro F, Buonsenso D, Salvi S, Del Giacomo P, et al. The diagnosis of pneumonia in a pregnant woman with coronavirus disease 2019 using maternal lung ultrasound. Am J Obstet Gynecol. 2020;223(1):9-11. https://doi. org/10.1016/j.ajog.2020.04.020.

182. Unger EC, Porter T, Culp W, Labell R, Matsunaga T, Zutshi R. Therapeutic applications of lipid-coated microbubbles. Adv Drug Delivery Rev. 2004;56(9):1291-314. https://doi.org/10.1016/j. addr.2003.12.006.

183. Huang P, Qian X, Chen Y, Yu L, Lin H, Wane L, et al. Metalloporphyrinencapsulated biodegradable nanosystems for highly efficient magnetic resonance imaging-guided sonodynamic cancer therapy. J Am Chem Soc. 2017;139(3):1275-84. https://doi.org/10.1021/jacs.6b11846.

184. Qian X, Zheng Y, Chen Y. Micro/nanoparticle-augmented sonodynamic therapy (SDT): breaking the depth shallow of photoactivation. Adv Mater. 2016;28(37):8097-129. https://doi. org/10.1002/adma.201602012.

185. Rosenthal I, Sostaric JZ, Riesz P. Sonodynamic therapy-a review of the synergistic effects of drugs and ultrasound. Ultrason Sonochem. 2004;11(6):349-63. https://doi.org/10.1016/j. ultsonch.2004.03.004.

186. Teranishi R, Matsuda T, Yuba E, Kono K, Harada A. Sonodynamic therapeutic effects of sonosensitizers with different intracellular distribution delivered by hollow nanocapsules exhibiting cytosol specific release. Macromol Biosci. 2019;19(4):1800365. https://doi.org/10.1002/mabi.201800365.

187. Liu MR, Khan AR, Ji JB, Lin GM, Zhao XG, Zhai GX. Crosslinked self-assembled nanoparticles for chemo-sonodynamic combination therapy favoring antitumor, antimetastasis management and immune responses. J Control Release. 2018;290:15064. https://doi.org/10.1016/j.jconrel.2018.10.007.

188. Kim S, Im S, Park EY, Lee J, Kim C, Kim TI, et al. Drug-loaded titanium dioxide nanoparticle coated with tumor targeting polymer as a sonodynamic chemotherapeutic agent for anticancer therapy. Nanomedicine. 2020;24:102110. https://doi. org/10.1016/j.nano.2019.102110.

189. Siddiqui MM, Rais-Bahrami S, Turkbey B, George AK, Rothwax J, Shakir N, et al. Comparison of MR/ultrasound fusion-guided biopsy with ultrasound-guided biopsy for the diagnosis of prostate cancer. JAMA. 2015;313(4):390-7. https://doi.org/10.1001/ jama.2014.17942.

190. Warner E, Plewes DB, Hill KA, Causer PA, Zubovits JT, Jong RA, et al. Surveillance of BRCA1 and BRCA2 mutation carriers with magnetic resonance imaging, ultrasound, mammography, and clinical breast examination. JAMA. 2004;292(11):1317-25. https://doi.org/10.1001/jama.292.11.1317. 
191. Yang JM, Favazza C, Chen RM, Yao JJ, Cai X, Maslov K, et al. Simultaneous functional photoacoustic and ultrasonic endoscopy of internal organs in vivo. Nat Med. 2012;18(8):1297-302. https:// doi.org/10.1038/nm.2823.

192. Furusawa Y, Fujiwara Y, Campbell P, Zhao QL, Ogawa R, Hassan MA, et al. DNA double-strand breaks induced by cavitational mechanical effects of ultrasound in cancer cell lines. PLoS ONE. 2012;7(1):e29012. https://doi.org/10.1371/journal.pone.0029012.

Publisher's Note Springer Nature remains neutral with regard to jurisdictional claims in published maps and institutional affiliations. 